Article

\title{
Durability Performance Evaluation of Rubberized Geopolymer Concrete
}

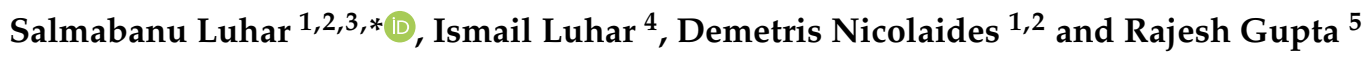 \\ 1 Frederick Research Center, P.O. Box 24729, Nicosia 1303, Cyprus; d.nicolaides@frederick.ac.cy \\ 2 Department of Civil Engineering, Frederick University, 1036 Nicosia, Cyprus \\ 3 Center of Excellence Geopolymer and Green Technology, School of Materials Engineering, \\ Universiti Malaysia Perlis (UniMAP), Perlis 01000, Malaysia \\ 4 Department of Civil Engineering, Shri Jagdishprasad Jhabarmal Tibrewala University, Rajasthan 333001, India; \\ jprraj2017@gmail.com \\ 5 Malaviya National Institute of Technology, Rajasthan 302017, India; rajesh.gupta@yahoo.co.in \\ * Correspondence: ersalmabanu.mnit@gmail.com
}

Citation: Luhar, S.; Luhar, I.;

Nicolaides, D.; Gupta, R. Durability

Performance Evaluation of

Rubberized Geopolymer Concrete.

Sustainability 2021, 13, 5969. https://

doi.org/10.3390/su13115969

Academic Editor:

Constantin Chalioris

Received: 18 March 2021

Accepted: 10 May 2021

Published: 25 May 2021

Publisher's Note: MDPI stays neutral with regard to jurisdictional claims in published maps and institutional affiliations.

Copyright: (c) 2021 by the authors. Licensee MDPI, Basel, Switzerland. This article is an open access article distributed under the terms and conditions of the Creative Commons Attribution (CC BY) license (https:// creativecommons.org/licenses/by/ $4.0 /)$

\begin{abstract}
Unfortunately, the production of cement impacts pessimistically on environments since it emits $\mathrm{CO}_{2}$-a principal Green House Gas (GHG) — encouraging the earth-heating dilemma. Moreover, it necessitates not only high temperature produced by the devouring of narrow natural mineral coal resources to obtain very high amounts of energy, but it also gulps down natural limestone deposits as a raw material that is found confined in nature to obtain intense energy. Quite recently, geopolymerisation - an exothermic process, through which geopolymeric binders can be produced by synthesis of a pozzolanic precursor rich in Alumina and Silica, for an instant, Fly Ash, with alkali solution for activation in an alkali medium at a low temperature and low operational energy-is recognized as a brilliantly promising alternative to conventional cement. That means, no elevated temperature and higher energy consuming reactions are essential any more as found associated with contemporary cement production. This research paper moves towards fulfilling the performance evaluation of durability studies viz., water permeability, sorptivity, sulphate resistance, acid resistance, salt resistance, chloride diffusion, drying shrinkage, and corrosion of fly ash based user and eco-friendly rubberized (containing rubber tyre fibres) geopolymer concrete. Comparisons of the outcomes have been made with its counterpart, which has unearthed that Rubberized Geopolymer Concrete proved to better concerning all the above-mentioned parameters than Rubberized OPC-Concrete.
\end{abstract}

Keywords: carbonation; water permeability; sorptivity; acid resistance; salt resistance; sulphate resistance; chloride diffusion; corrosion resistance; geopolymer

\section{Introduction}

Even though Portland cement is an excellent and vital binder for construction composites but unfortunately, its present production process is highly energy consuming [1] and on the top of that, it emits approximately one tonne of $\mathrm{CO}_{2}$ for the production of each ton of Portland cement [2,3]. Not only that, the process also gulps down confined natural rock resources of limestones as raw material and mineral coals as fuel to obtain the elevated temperatures essential for calcination [3]. All these challenges have compelled world researchers to develop new, user and eco-friendly alternative construction materials with reduced energy and low levels of carbon footprints, which can desirably integrate with profound diverse wastes while keeping the performance of the resulting building materials as high as or even higher than the ordinary Portland cement system [4]. Nowadays, the innovative green Geopolymer technology is eye-catching due to its outstanding performances of Geopolymer construction composites like nine times lesser $\mathrm{CO}_{2}$ emissions, and six-fold lower operational energy consumption [2], preventing the degradation of 
natural limited resources and providing relief to the global warming dilemma. On the other hand, over the past couple of centuries, the significance of natural rubber has come to light as a useful product for mankind and it has been ever-increasing. Following the International Rubber Research Group, the total global consumption of rubber in 2018 was predicted to escalate by $3.4 \%$ or 29.39 million tonnes, and the prediction was expected to rise by $2.5 \%$ or 30.12 million tonnes in the year $2019[5,6]$. In harmony with the data of the Association of Natural Rubber Producing Countries (July 2019) (ANRPC) [7], the consumption of rubber-both synthetic and natural - was 29.2 million tonnes in the year 2018, counting 13.72 million tonnes of natural rubber. Another report from July 2018 stated that the worldwide production of natural rubber is 7.37 million tonnes with an expansion of $3.7 \%$ in the initial seven months in 2018 [6]. The natural rubber utilization has been ascended by $5.2 \%$ and achieved 8.16 million tonnes in starting seven months. The total world production of rubber during 2013 was estimated to be over 27 million tonnes, rising at a yearly average rate of $3 \%$ from 22.44 million tonnes in 2006 [7]. The total production of Malaysian Rubber in 2013 was 0.933 million tonnes. [8]. This rubber production is useful for producing tyres and other industrial and consumer products [9]. Browsing the history of the rubber tyres, they are the result of research investigations and upgrading over the past century. In 2019, the ongoing exigency for tyres is predicted to touch the mark of 3 billion units, which demonstrates a yearly rise of $4 \%$ and a sales guess of 258 billion USD $[10,11]$. The incessant developments and improvements make the tyre a well-designed and elegant piece of technology rather than simply a rubber piece. The astonishing boost in the number of vehicles augments day by day worldwide due to improvement of economics and necessity to transport mostly cities around the world. That is why, over the years, the escalating mammoth quantity of discarded rubber vehicle tyres generated during new production as well as the end-of-life rubber tyres [12] are accumulated globally and mostly disposed of unsystematically into landfills as a solid waste, which is a major alarming threat to environments [13,14]. These huge accumulations of wastes rubber tyres have turned into a gigantic impasse surrounding their waste disposal management [15].

Geopolymers are a novel hope for researchers as they exhibit low carbon footprint, excellent strength, durability, thermal, freeze-thaw, etc., attributes, putting them forward as promising sustainable construction materials [1,16-20]. They are inorganic polymers developed by the chemical reaction amid Alumina and Silica-rich precursor and alkali activators through an exothermic process of geopolymerisation at low temperature in an alkaline medium [15,17-20] using lower operational energy.

Fly Ash is a pozzolanic industrial by-product found in profuse amounts, filling lands and creating health hazards. Additionally, this copious solid waste generating mostly from thermal power stations contaminates air, soils, surface, and sub-surface water. Apart from it, used and discarded rubber tyre wastes from the automobile industry is also a great challenge to the environment and general health of lives on the planet as they possesses a complicated chemical structure and are not degradable under normal conditions. Furthermore, they liberate toxic gases on burning, causing asthmatic and skin problems. U.S.A. alone generates rubber tyre wastes of more than 300 million tyres per year and the European Union generates 180 million [18-20]. This huge waste must be resolved to manage its expansive growth, prevent it from filling landfills, and save the earth from pollution. One systematic way to use it in the manufacturing of Geopolymer concrete (GPC) is, as a replacement material to natural sand [17-19]. It will not only manage this gargantuan waste but it will also conserve natural sand resulting in a development of Rubberized Geopolymer Concrete (RGPC). However, to be established as a durable construction material, RGPC has demonstrated excellent strength and durability which is quite essential to be considered as an approved building material. The incorporation of rubber tyre wastes with GPC has proven itself a durable product which exhibits brilliant durability attributes too. Also, RGPC has evidently proved as a sustainable building material under laboratory investigations. 


\section{Materials Descriptions and Mix Proportions}

\subsection{Raw Materials}

For the production of RGPC, rubber tyre fibres procured from tyre waste grinding unit as well as Class F type fly ash were used to confirm the Indian standard IS 3812 [21]. Table $1[18,22]$ displays the chemical composition of fly ash. To partly substitute river sand, rubber fibres (10,20, and 30\% substitution) with a specific gravity of 1.09 and $8-10$ aspect ratio, the rubber fibres were almost $2-4 \mathrm{~mm}$ thick and up to $22 \mathrm{~mm}$ in length were used. The particle distribution curve for the rubber fibres is lying Zone II, as shown in Figure 1 according to IS: $383-1970$ [23]. The fineness modulus -2.56 , specific gravity -2.61 as well as water absorption $-0.5 \%$ pragmatized. The sand of the river meets zone II according to IS: 383-1970 [23]. The superplasticizer based on naphthalene sulphonate was employed to accomplish the anticipated workability. The fly ash XRD is displayed in Figure 2.

Table 1. Fly ash- Physical characteristics and chemical configurations * [18,22].

\begin{tabular}{cccc}
\hline Sr. No. & Composition & Unit & Obtain Value \\
\hline 1 & Specific Surface area & $\mathrm{m}^{2} / \mathrm{kg}$ & 428 \\
2 & Autoclave Expansion & $\%$ & 0.024 \\
3 & Moisture Content & $\%$ & 0.23 \\
4 & Reactivity of Lime & $\mathrm{N} / \mathrm{mm}^{2}$ & 6.60 \\
5 & Chemical Analysis & $\%$ & \\
& Ignition Loss & $\%$ & 0.94 \\
& Addition of Silica, Alumina, and ferric oxide content & 92.26 \\
& Silica & $\%$ & 58.88 \\
& Magnesium oxide & $\%$ & 1.64 \\
& Sulfur trioxide & $\%$ & 0.74 \\
& Sodium oxide & $\%$ & 0.50 \\
& Total content of Chlorides & 0.025 \\
\hline
\end{tabular}

* Provided by manufacturer.

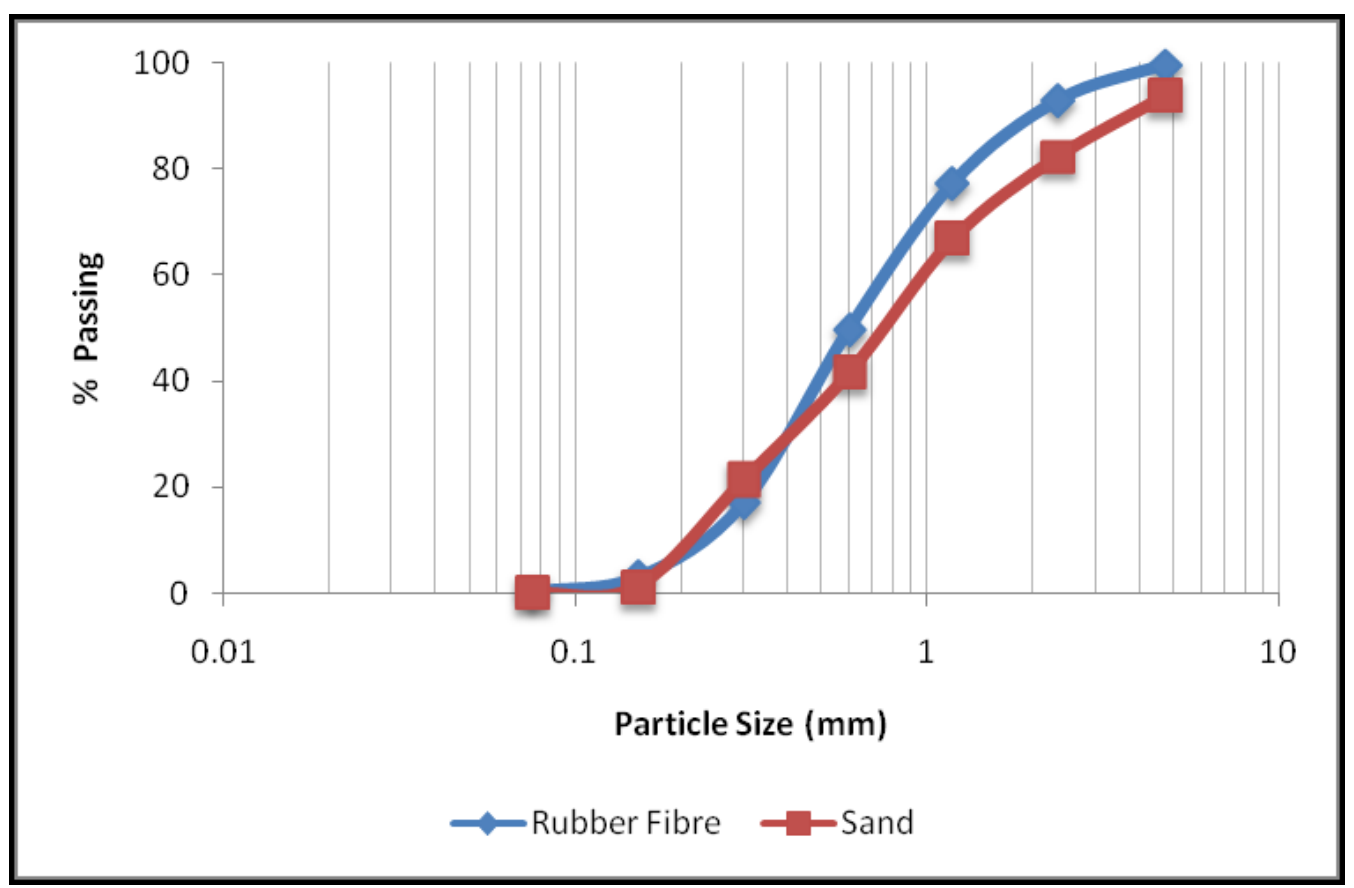

Figure 1. Particle size distribution curve $[18,22]$. 


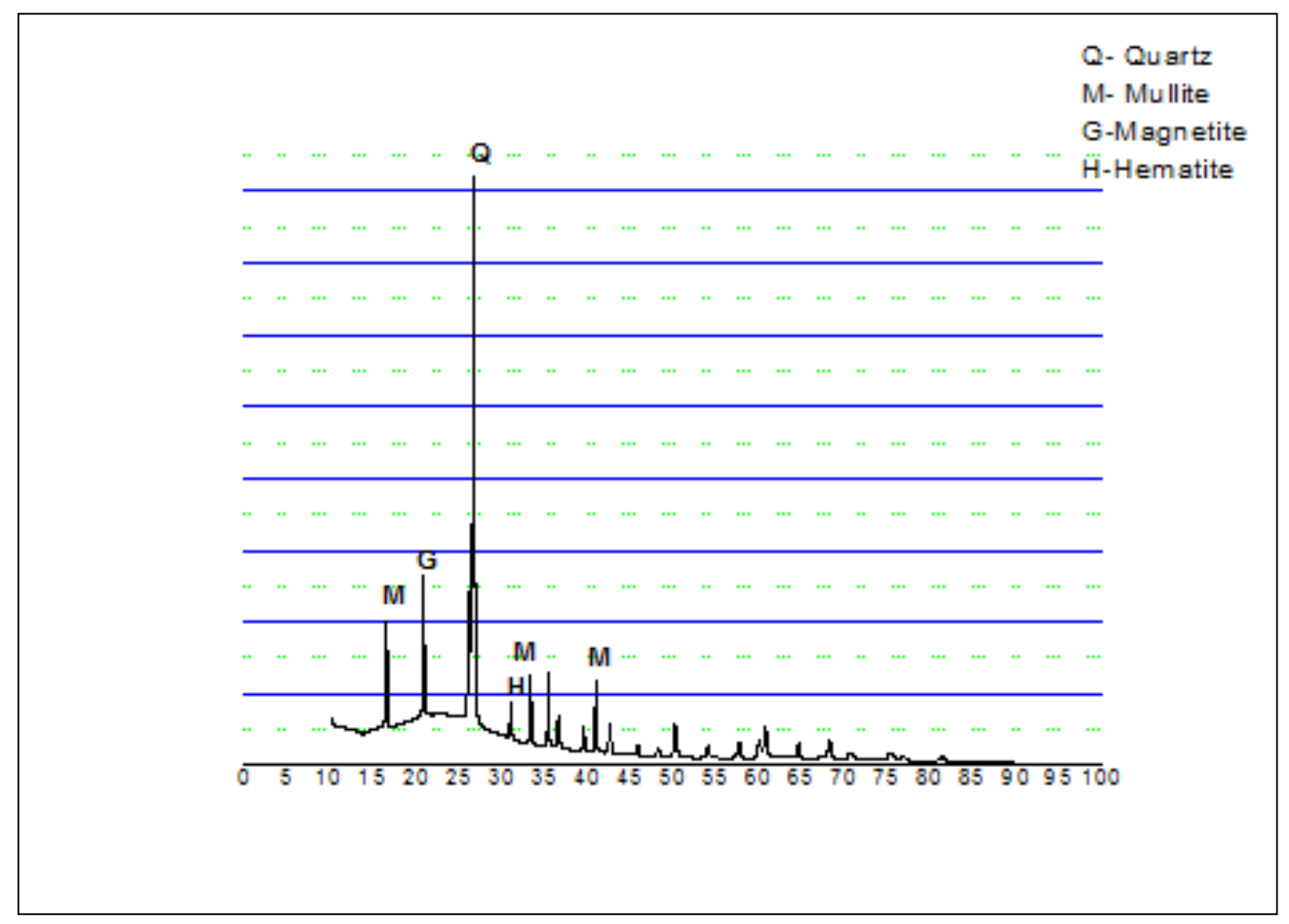

Figure 2. X-ray diffraction analysis of fly ash $[18,22]$.

\subsection{Mix Proportions}

Table 2 demonstrate the parameters used for this study. Based on this mixing design method, the final mass of the parts was calculated as outlined in Table 3. The OPC concrete mix was calculated as per IS 10262-2009 [24]. Table 3 lists the OPC concrete mix. The fine aggregate in concrete was partially substituted with waste rubber tyre fibres.

Table 2. The following parameters were used for this research study [19].

\begin{tabular}{ccc}
\hline Sr.No & Parameters & Value \\
\hline 1. & Sodium silicate -Sodium hydroxide ratio & 2.5 \\
2. & Additional water content & $5 \%$ \\
3. & Curing time & $48 \mathrm{~h}$ \\
4. & Alkaline liquid to fly ash ratio & 0.4 \\
5. & Sodium hydroxide Concentration & $14 \mathrm{M}$ \\
6. & Rest period & 1 day \\
7. & Admixture dosage & $2 \%$ \\
8. & Curing temperature & $90^{\circ} \mathrm{C}$ \\
\hline
\end{tabular}

Table 3. Mix the proportion of design (per $\mathrm{m}^{3}$ ).

\begin{tabular}{|c|c|c|c|c|c|c|c|c|c|c|}
\hline \multirow{2}{*}{$\begin{array}{c}\text { Mix } \\
\text { Praportion }\end{array}$} & \multirow{2}{*}{$\begin{array}{l}\text { Rubber } \\
\text { Fiber }\end{array}$} & \multirow{2}{*}{$\begin{array}{c}\text { Fine } \\
\text { Aggregate } \\
\mathrm{kg} / \mathrm{m}^{3}\end{array}$} & \multirow{2}{*}{$\begin{array}{l}\text { Fly ash } \\
\mathrm{kg} / \mathrm{m}^{3}\end{array}$} & \multirow{2}{*}{$\begin{array}{l}\text { Cement } \\
\mathrm{kg} / \mathrm{m}^{3}\end{array}$} & \multicolumn{2}{|c|}{$\begin{array}{c}\text { Coarse } \\
\text { Aggregate kg/m }\end{array}$} & \multirow{2}{*}{$\begin{array}{l}\mathrm{NaOH} \\
\mathrm{kg} / \mathrm{m}^{3}\end{array}$} & \multirow{2}{*}{$\begin{array}{c}\mathrm{Na}_{2} \mathrm{SiO}_{3} \\
\mathrm{~kg} / \mathrm{m}^{3}\end{array}$} & \multirow{2}{*}{$\begin{array}{c}\text { Admixture } \\
\mathrm{kg} / \mathrm{m}^{3}\end{array}$} & \multirow{2}{*}{$\begin{array}{c}\text { Water } \\
\text { Content } \\
\mathrm{kg} / \mathrm{m}^{3}\end{array}$} \\
\hline & & & & & $20 \mathrm{~mm}$ & $10 \mathrm{~mm}$ & & & & \\
\hline GP-0 & 0.0 & 656.25 & 446.43 & - & 731.25 & 487.5 & 51.02 & 127.55 & 8.93 & 22.32 \\
\hline GP-10 & 26.9 & 629.35 & 446.43 & - & 731.25 & 487.5 & 51.02 & 127.55 & 8.93 & 22.32 \\
\hline GP-20 & 53.80 & 602.55 & 446.43 & - & 731.25 & 487.5 & 51.02 & 127.55 & 8.93 & 22.32 \\
\hline GP-30 & 80.71 & 575.64 & 446.43 & - & 731.25 & 487.5 & 51.02 & 127.55 & 8.93 & 22.32 \\
\hline CC-0 & 0.0 & 656.25 & - & 446.43 & 731.25 & 487.5 & - & - & 8.93 & 160.71 \\
\hline CC-10 & 26.9 & 629.35 & - & 446.43 & 731.25 & 487.5 & - & - & 8.93 & 160.71 \\
\hline CC-20 & 53.80 & 602.55 & - & 446.43 & 731.25 & 487.5 & - & - & 8.93 & 160.71 \\
\hline CC-30 & 80.71 & 575.64 & - & 446.43 & 731.25 & 487.5 & - & - & 8.93 & 160.71 \\
\hline
\end{tabular}




\subsection{Details of the Experiment}

Durability testing in compliance with norms has been carried out (see Table 4). The information is shown in Table 4.

Table 4. Details of Experimental Research.

\begin{tabular}{cccc}
\hline \multirow{2}{*}{$\begin{array}{c}\text { Properties } \\
\text { Evaluation }\end{array}$} & Experiments & Age of Testing (Days) & Standards \\
\hline & Water Permeability & 28 & DIN-1048 \\
\cline { 2 - 4 } & Shrinkage & $7,14,21,28,35,49,63,77,91,180,365$ & - \\
\cline { 2 - 4 } & Sorptivity & $28,90,365$ & ASTM C 1585-04 \\
\cline { 2 - 4 } \begin{tabular}{l} 
Purability \\
\cline { 2 - 4 }
\end{tabular} & Carbonation resistance & $14,21,28,35,42,56,90$ & CPC-18 RILEM \\
\cline { 2 - 4 } & Salt attack resistance & $7,28,84,162,365$ & Past literature \\
\cline { 2 - 4 } & Sulphate attack resistance & $7,28,84,162,365$ & Past literature \\
\cline { 2 - 4 } & Acid attack resistance & $7,28,84,162,365$ & Past literature \\
\cline { 2 - 4 } & Corrosion resistance & $30,60,90,120,150,180$, & ASTM G-109 \\
& & $210,240,270,300,330,360$ & ASTM C 876-15 \\
\cline { 2 - 4 } & Chloride Diffusion & 28 & ASTMC-1556 \\
\hline
\end{tabular}

\section{Durability Experiments Methods}

Concrete durability is described as its capability to withstand weathering, abrasion, chemical attachments, or other deterioration processes.

\subsection{Water Permeability}

The capacity of a fluid to pass through concrete is described by permissibility. It is the key durability parameter. Tests were performed as per DIN 1048-1991 [25]. Concrete cubes of $150 \times 150 \times 150 \mathrm{~mm}$ size were dried in a drying chamber for 14 days. The depth of water permeation inside the concrete under sustained pressure was inspected from this test. A sustained pressure of 5 bars $\left(0.5 \mathrm{~N} / \mathrm{mm}^{2}\right)$ was applied in the vertical plane along the mould filled direction for three days. The penetration depth was evaluated after three days by half dividing the cube. The average penetration depth of three cubes was regarded.

\subsection{Carbonation}

The calculation is the gradual neutralisation of the alkali from external sources (primarily atmospheric carbon dioxide) in the concrete cover with acidic gasses. This test method involves determining, by way of an indicator, the depth of the carbonated layer on the surface of hardened concrete. The $100 \mathrm{~mm}^{3}$ cubes were divided into four prisms sized $50 \times 50 \times 100 \mathrm{~mm}$ to perform the accelerated carbonation test. Each prism specimen was allowed to dry in a drying chamber for 2 weeks until a persistent weight was accomplished. After drying, two coats of epoxy paint were applied on the longitudinal side of the specimens to resist the penetration of carbon dioxide, leaving the top and bottom sides of each specimen to be penetrated by carbon dioxide. The samples were held in a carbonation chamber. A 5\% -carbon dioxide, relative humidity- $50 \pm 5 \%$, and temperature- $25 \pm 1{ }^{\circ} \mathrm{C}$ are maintained by the carbonating chamber. After 14,21, 28, 35, 42, 56, and 90 days of $\mathrm{CO}_{2}$ exposure, carbon concentration depth was measured. The depth of carbonation was measured by splitting the specimens in half and instantly spraying a phenolphthalein indicator over the broken surface. By blending $1 \%$ phenolphthalein in $70 \%$ ethyl alcohol, the indicator was made. The carbonation depth from the top and bottom of the sample was evaluated after praying the indicator. The average of three specimen readings was considered to be the depth of carbonation of that mix. 


\subsection{Drying Shrinkage}

This test examined the effect of rubber tyre fibre replacement on the shrinkage of geopolymer concrete as well as cement concrete. Each mix was moulded with three prisms of $75 \times 75 \times 285 \mathrm{~mm}$ in size. After curing, Demec studs were pasted $212 \pm 1 \mathrm{~mm}$ apart on the uppermost surface of each sample. Shrinkage strain was measured using a mechanical strain gauge three days after casting. The next shrinkage strain measurement was taken 4 days after casting, and this was considered to be the first-day shrinkage measurement of the specimen. In the first week, measures were taken every day, from 1 to 4 weeks, once every 2 weeks up to 12 weeks, and then once in 4 weeks. The gauge has a minimum resolution of $0.002 \mathrm{~mm}$. Specimens were maintained at a laboratory room temperature at $25{ }^{\circ} \mathrm{C}$ with a relative humidity of $50-60 \%$.

\subsection{Sulfate Resistance}

The resistance against sulphate of the control geopolymer concrete and cement concrete was inspected through the change in mass as well as residual compressive strength. Cubes of $100 \times 100 \times 100 \mathrm{~mm}$ have been cast to assess weight and residual compressive strength. After curing, each specimen was weighed to give an initial weight. Seven days after curing, the samples were submerged in a $5 \%$ concentration of sodium sulphate solution. The volume of sodium sulphate was calculated based on the volume of sulphate solution: the volume of the specimen (4:1 ratio).

The solution was swapped every month to maintain its concentration. The mass change, length change, and residual compressive resistance changes were evaluated after exposure to $7,28,84,162$, and 365 days. The remaining compressive strength was assessed after exposure by checking the samples in saturated dry surface conditions (SSD). To measure the change in mass, samples were detached from the solution, wiped properly, and their mass was measured. The specimens were then returned to soak in the sulphate solution. A mechanical strain gauge was used to measure the shift in length.

\subsection{Acid Resistance}

Resistance against acid was evaluated using geopolymer and cement concrete samples$100 \times 100 \times 100 \mathrm{~mm}$ in size. Solutions of $3 \%, 5 \%$, and $10 \%$ concentrated sulfuric acid were produced to examine the upshot of acid on the specimens. The original weight or dry weight was assessed for 7, 28, 84, 162, and 365 days after casting, and then the specific samples were taken in the solution. At every selected exposure period, the mass change and residual compressive strength were measured. The solution was removed weekly and substituted each month to preserve the $\mathrm{pH}$ level. The volume of solution was determined based on the solution volume to the specimen volume (4:1ratio). The samples were separated from the solution and wiped off to remove the solution from the surface after the chosen phases of exposure. The weight of the specimens was measured in SSD condition and the residual compressive strength was tested.

\subsection{Salt Attack Resistance}

Salt attack resistance was measured using $100 \times 100 \times 100 \mathrm{~mm}$ cubes for 7, 28-, 84-, $162-$, and 365-days exposure periods. A solution was prepared with a $5 \%$ concentration of sodium chloride. After curing, the specimens were weighed to determine their initial weight. The specimens were then engrossed in solution for a selected exposure period. The mass change and residual compressive strength were investigated from this test. Specimens have been removed, wiped, and weighed to alter the mass. The samples were evaluated in SSD conditions for the change in compressive strength.

\subsection{Water Sorptivity}

Water sorptivity experiments were performed to assess the absorbance level (sorptivity) of water by capillary concrete suction. The experiments were done following the requirements of ASTM C1585-04 [26]. This experiment was carried out using specimens 
with a diameter of $100 \pm 6 \mathrm{~mm}$ and a height of $50 \pm 3 \mathrm{~mm}$. This test included samples placed at $50 \pm 2{ }^{\circ} \mathrm{C}$ in a desiccator. To control the relative humidity, potassium bromide solution was placed in the bottom of the desiccator in such a way that the test specimens could not contact the solution. Each specimen was placed in the desiccator for up to three days. Afterwards, the sample was positioned inside a sealable ampoule to prevent contact with free air. At least 15 days before the sorptive procedure, the container is stored at $23 \pm 2{ }^{\circ} \mathrm{C}$. Specimens have been removed from storage, and before sealing, their mass was registered. The bottom and side surfaces of each sample were wrapped with a sealing material. The measurement of the mass in each given sample was done as the original mass for calculations of water sportiveness. The bars were positioned on the bottom of a pot for assistance. The plate was filled to $1-3 \mathrm{~mm}$ above the top of the support bars with distilled water. The original contact time and date with water have been registered. The masses were registered at the $60 \mathrm{~s}, 5 \mathrm{~min}, 10 \mathrm{~min}, 20 \mathrm{~min}, 30 \mathrm{~min}, 60 \mathrm{~min}$, and then up to $6 \mathrm{~h}$, once a day for a week. One final reading was taken on day 9. To weigh the specimens, they were taken from the tray, excess water removed, and their dry surface placed on an electronic pan balance. The engrossing surface was not touched, and the specimen was returned to the tray within $15 \mathrm{~s}$.

\subsection{Chloride Ion Migration}

This test examined the resistance of the concrete samples against chloride ion penetration. This experiment consisted of concrete codes with a diameter of $60 \mathrm{~mm}$ and a height of $150 \mathrm{~mm}$. With the assistance of a cutting saw machine, each core was sliced to a thickness of $40 \mathrm{~mm}$. The side and ends of the specimen were covered with silicon sealant and masking tape, respectively. The specimen was then mounted on top and bottom with a rubber gasket and masking tape before being immersed in distilled water. The chloride cell consisted of two parts: an upstream part acting as the anode was occupied with $3 \%$ sodium chloride solution concentration; a distilled water portion was loaded downstream to function as a cathode. A possible distinction of $30 \mathrm{~V}$ DC was implemented between the migrating cells. The chloride ion concentration was examined in the upstream cell using a titration method. Similarly, in the downward part, the chloride ion concentration was calculated every $4 \mathrm{~h}$ until the steady-state condition was reached. The titration process was performed by taking $20 \mathrm{~mL}$ solution samples from the downstream cell and adding an indicator of potassium chromate. Silver nitrate solution $(0.0141 \mathrm{~N})$ was then slowly added to the ask until the solution had a reddish tinge, and the volume of silver nitrate was recorded. The concentration of chloride ion in the downstream cell was calculated as the steady-state chloride diffusion coefficient Dssm was assessed,

$$
\mathrm{D}_{\mathrm{ssm}}\left(\frac{\mathrm{m}^{2}}{\mathrm{~s}}\right)=\frac{\mathrm{RTL}}{\mathrm{ZF} \Delta \mathrm{E}} \mathrm{J} / \mathrm{C}_{1}
$$

where,

$\mathrm{T}=$ Initial and final temperature average value, in anolyte solution $(\mathrm{K})$,

$\mathrm{R}=$ Constant of Gas= $8.314 \mathrm{~J} /\left(\mathrm{K}_{\mathrm{mol}}{ }^{-1}\right)$

$\mathrm{L}=$ Sample thickness, $\mathrm{m}$,

$\mathrm{Z}=$ Ion valence's absolute value (for chloride, $\mathrm{Z}=1$ )

$\mathrm{F}=$ Constant of Faraday $=9.648 \times 10^{4} \mathrm{~J} /(\mathrm{V} . \mathrm{mol})$,

$\mathrm{J}=$ chloride flux, $\mathrm{J}\left(\mathrm{mol} / \mathrm{cm}^{2} \mathrm{~s}\right)$

$\mathrm{C}_{1}=$ Chloride ions activity

$\Delta \mathrm{E}=$ absolute potential difference of the solution as upstream and downstream measured by the use of two reference electrodes.

\subsection{Corrosion}

To study the resistance of concrete to steel corrosion, a chloride-induced corrosion technique was employed. To examine the corrosion induced by embedded steel in concrete, 
we used a macro-cell corrosion method and a half-cell potential method. In these methods, $12 \mathrm{~mm}$ diameter Thermo mechanically treated reinforcements of a length of $350 \mathrm{~mm}$ were first cleaned using a wire brush. Then, $70 \mathrm{~mm}$ at the apiece end of the bar was coated with epoxy paint to prevent corrosion of that portion of the bar outside the specimen. Specimens of $250 \times 205 \times 135 \mathrm{~mm}$ with a ponding well of $15 \mathrm{~mm}$ at the top were cast. The bars were arranged such that $350 \mathrm{~mm}$ of their length was within the sample, with one bar centrally placed at the top as well as two bars placed with $30 \mathrm{~mm}$ cover at the bottom, such that the middle portion of the bars ( $210 \mathrm{~mm}$ length) was exposed to corrosion and $70 \mathrm{~mm}$ protruded from each side of the concrete specimen. The upper bars were the anode, and the lower bars were the cathode. The reinforcement bars were weighed adequately before casting the corrosion samples. The bottom and lateral faces of the samples were covered with epoxy after curing. In a temperature and humidity-controlled space, specimens were maintained. The electrical connection between the anode and cathode was ensured utilizing a soldered wire. Between the top and bottom bars, a $100 \mathrm{~mm}$ resistor was linked. A 3\% concentration of sodium chloride solution filled the $15 \mathrm{~mm}$ depression at the top of each specimen, and alternating cycles of wetting and drying were conducted for up to 2 weeks.

To assess the potential difference between the anode and cathode bar in the resistor with a voltmeter, the macro cell corrosion experiment was used. The test was conducted as per ASTM G 109 [27]. An initial reading was taken 7 days after ponding the sodium chloride over the specimen. The terminal of the voltmeter was connected with the bottom bars for reading. A negative voltage link to the positive Galvanic current, i.e., the anode at the top of the bar. Every month, over 12 months, readings were taken. The macro-cell current was calculated as

$$
I_{j}=\frac{V_{i}}{100}
$$

where as,

$\mathrm{I}_{\mathrm{j}}=$ Macro-cell current

$\mathrm{V}_{\mathrm{j}}=$ Voltage measured over $100 \Omega$ resistor

Half-cell potential measurements were done at the top steel bar according to the reference copper-copper sulphate electrode (CSE) by immersing it in a 3\% concentrated $\mathrm{NaCl}$ solution. The top and bottom bars were separated before the reading and the current could be stabilized. A voltmeter was used to read the potential once a month. The possibility of corrosion based on the value of potential difference concerning CSE was measured as per ASTM C 876 [28]. If the potential over an area is higher than $-200 \mathrm{mV}$, there is a chance of there being no reinforcing corrosion in that area of more than $90 \%$ when the measurement is made. If the potential of the reinforcing steel in that region is between -200 to $-350 \mathrm{mV}$, corrosion in that region is uncertain. When the potential for a region is less than $-350 \mathrm{mV}$, it is more than $90 \%$ likely that steel corrosion will be reinforced when the measurement is carried out in that region.

\section{Results and Discussion}

\subsection{Water Permeability}

Permeability was evaluated in terms of the depth of water penetration. The depth of penetration of the water in terms of rubber fibre content demonstrates variety in Figure 3. The water penetration depth increases as the content of rubber fibre are increased. In geopolymer concrete, the water penetration is smaller than in OPC concrete. In a prior study, a similar outcome was noted [29]. The continuous chemical reaction amid fly ash as well as alkaline solution results in a change in porosity and creates denser pores in geopolymer concrete $[29,30]$. However, a detailed examination found that the variations were very small in the case of geopolymer concrete. Minimum and maximum water penetration values of $31.2 \mathrm{~mm}$ and $35.7 \mathrm{~mm}$ occur in the geopolymer concrete. 


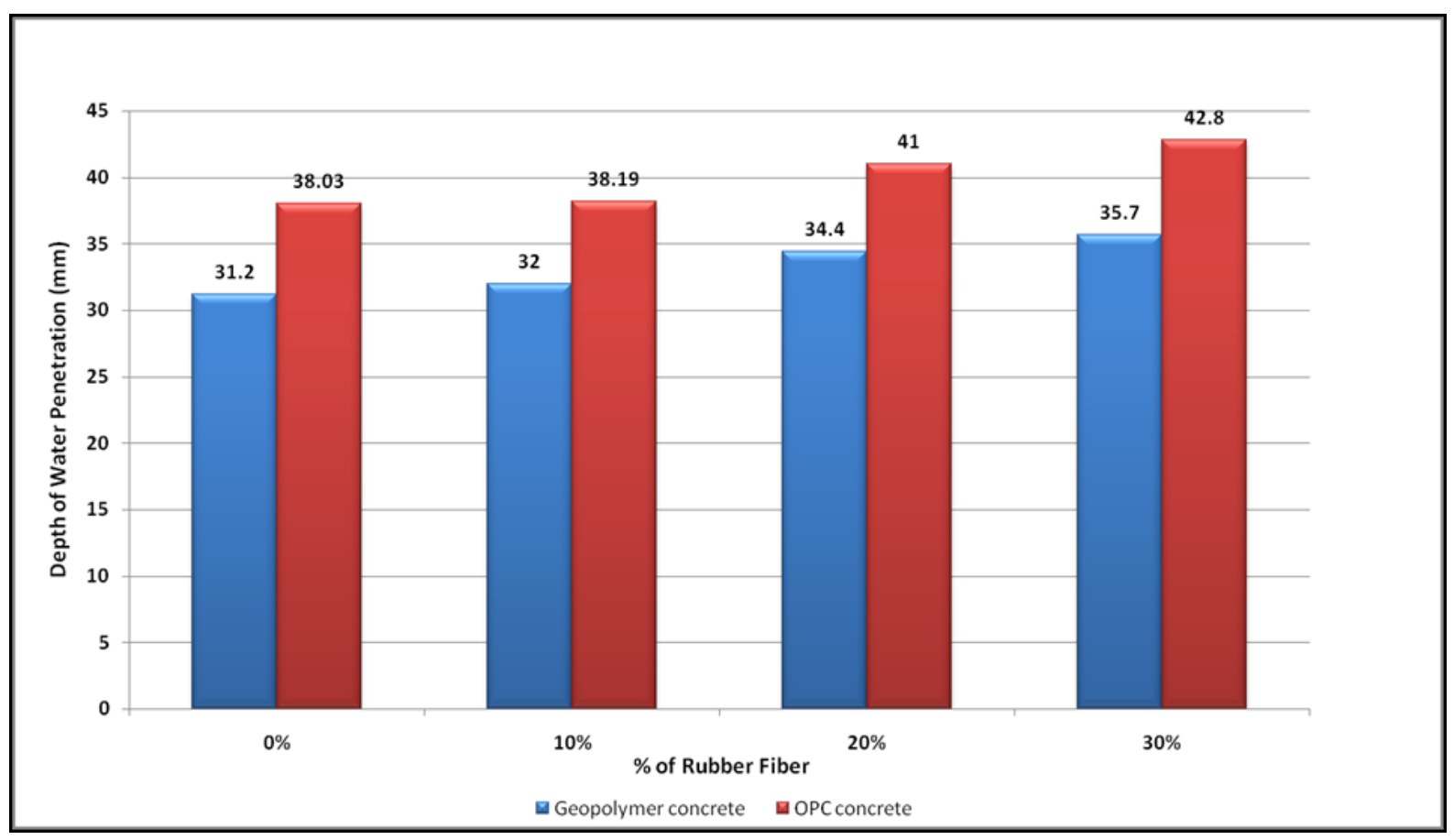

Figure 3. Water permeability of geopolymer and OPC concrete.

The rise in penetration depth may be ascribed to the rise of concrete porosity, which can be seen at greater rubber fibre replacement rates. In OPC concrete, the minimum and maximum water penetration are $38.03 \mathrm{~mm}$ and $42.8 \mathrm{~mm}$, respectively. The development of pores is dependent on the alkaline solution, aggregate, and source materials. Unlike the OPC concrete, which undergoes a hydration process, the pores in the geopolymer are filled by alumino-silicates. This lower permeability of geopolymer concrete has led to it being referred to as "excellent" concrete [29,31].

\subsection{Sorptivity}

Sorptivity measures the transport properties of concrete by which water passes through capillary pores into the concrete. Figures 4 and 5 illustrate the sorptivity index of geopolymer as well as OPC concrete. From Figure 4, it is possible to conclude that the geopolymer concrete has lower sorptivity $\left(0.09-0.164 \mathrm{~mm} / \mathrm{min}^{0.5}\right)$ than OPC concrete $\left(0.113-0.203 \mathrm{~mm} / \mathrm{min}^{0.5}\right)$ after 28 days. A similar observation was recorded in previous research [32]. The limit of the sorptivity index is below $0.200 \mathrm{~mm} / \mathrm{min}^{0.5}$, which is the recommended value for concrete according to previous research [32]. The control geopolymer concrete has a sorptivity index of $0.09 \mathrm{~mm} / \mathrm{min}^{0.5}$ after 28 days (Figure 5).

This fact indicates that few capillary pores exist following the effective reaction amid the alkaline solution as well as source material, whereas capillary pores persist in the OPC concrete to enable the hydration of the cement. Additionally, as the rubber fibre content is increased, the sorptivity index is increased for both the concrete (geopolymer and OPC). Hence, geopolymer concrete has fewer capillary pores than OPC concrete. This results in a slower rate of sorptivity into the geopolymer concrete compared with OPC concrete. 


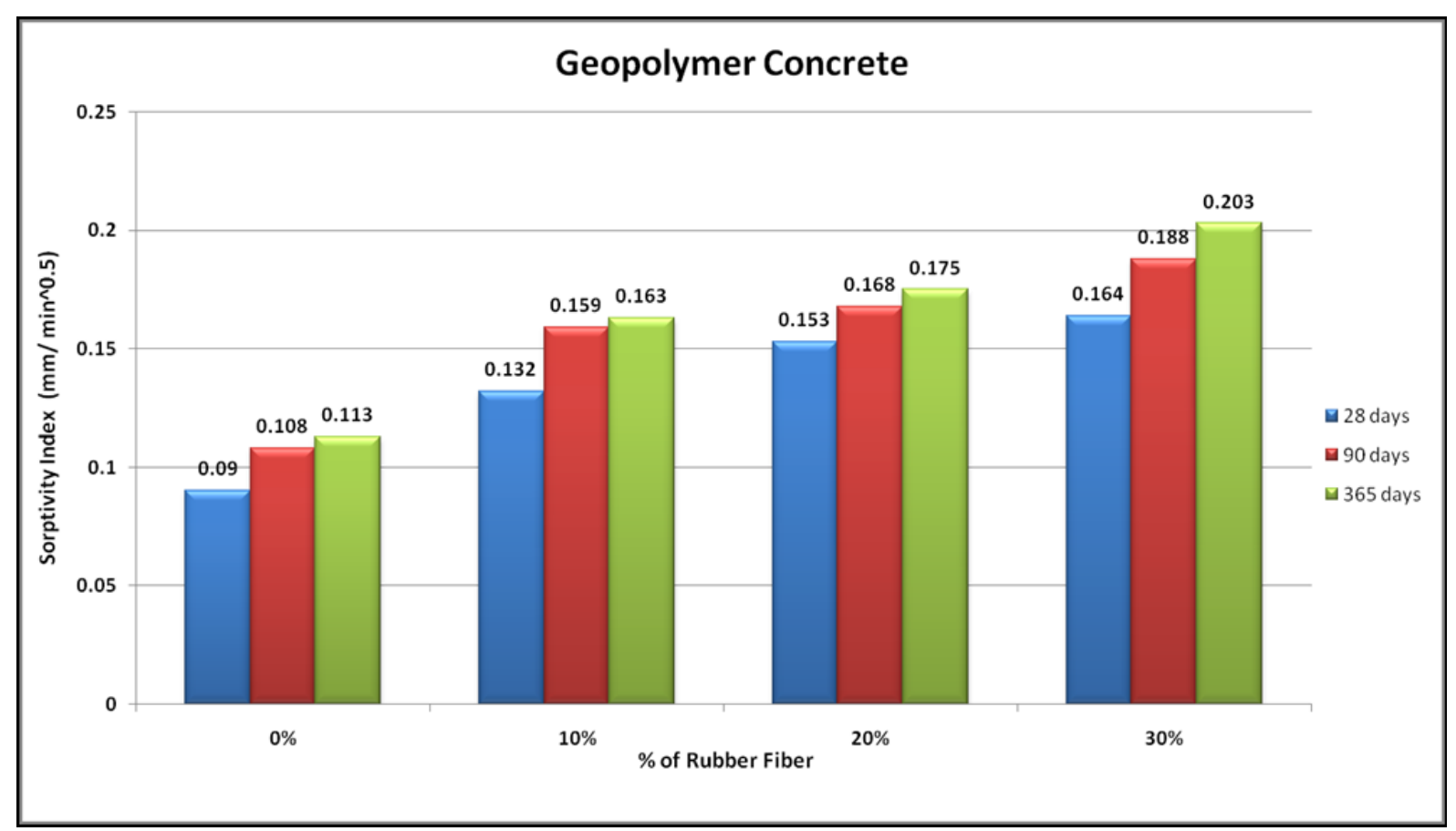

Figure 4. Sorptivity of geopolymer concrete.

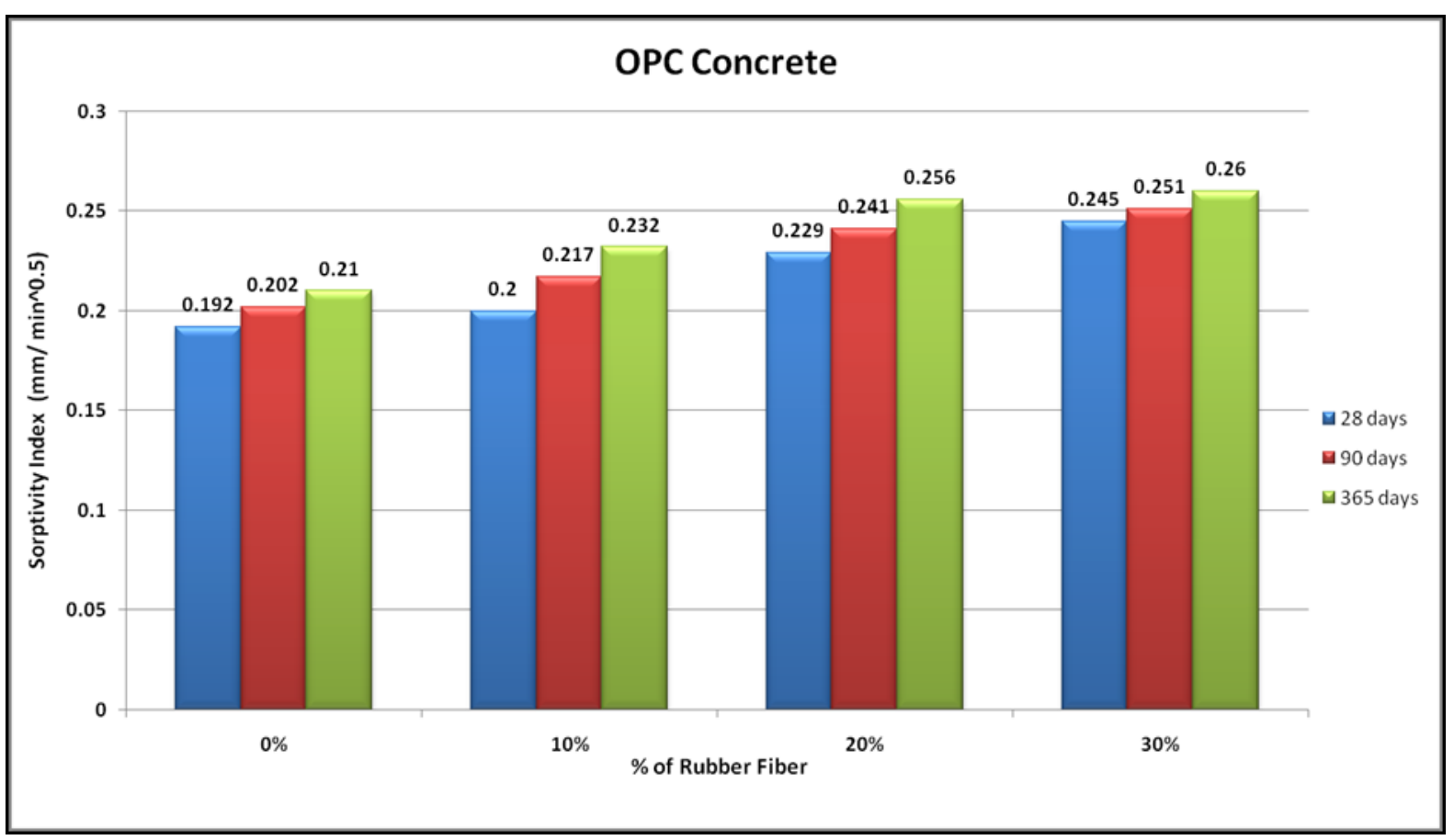

Figure 5. Sorptivity of OPC concrete.

\subsection{Sulfate Resistance}

On geopolymer concrete and OPC cement, the sulphate resistance test has been performed. The experiment was carried out with samples soaked in $5 \% \mathrm{Na}_{2} \mathrm{SO}_{4}$ (sodium sulphate) solution. After exposure periods of 7, 28,84, 162, and 365 days, the sulphate resistance was assessed based on changes in physical appearance, mass, length, and compressive strength. Samples were also soaked in distilled water for comparison. Following one year of exposure, the physical appearance of the geopolymers is shown in Figure 6. No modifications were noted in the geopolymer samples after exposure to sodium sulphates 
for up to one year. The OPC concrete specimen was, by comparison, widened and often randomly cracked. Similar observations in prior studies have been recorded [33].

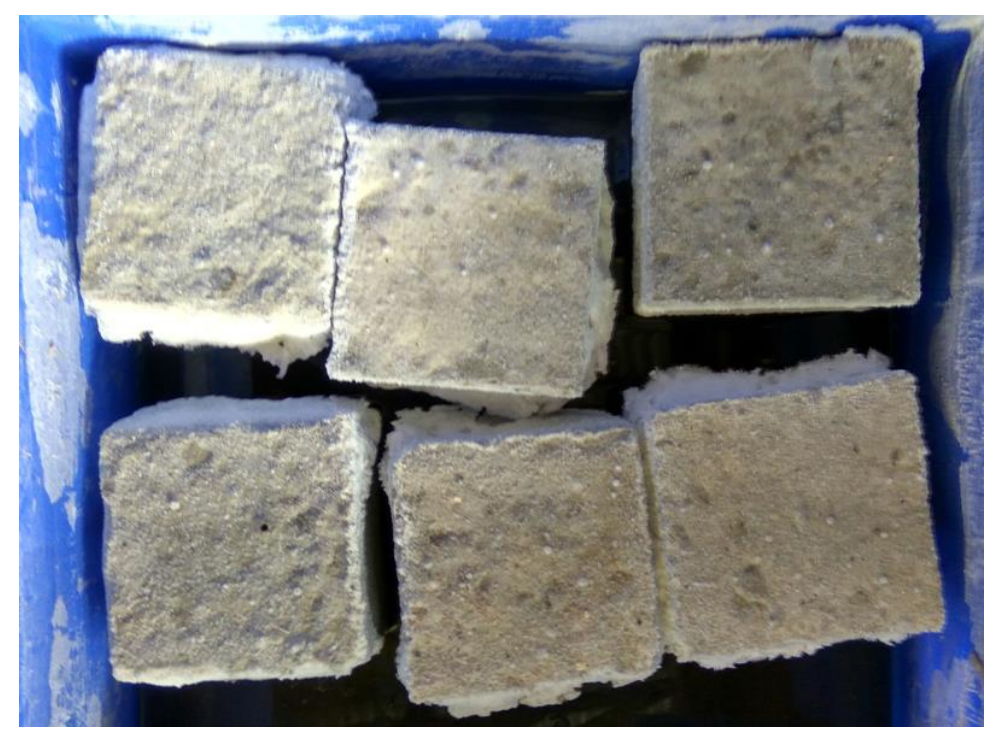

Figure 6. Physical appearance of geopolymer and OPC concrete.

Figure 7 illustrates the mass change of geopolymer concrete specimens subsequently sodium sulphate exposure up to one year. It can be seen that there has been no significant change in mass in the geopolymer specimen, whereas the mass of the OPC concrete specimen (Figure 8) has increase initially due to fascination of sodium sulphate solution and degradation of mass observed due to the effect of sodium sulphate solution shown in Figure 8. A significant increase in mass was observed in the geopolymer specimen as a result of the absorption of liquid through geopolymer specimens. The absorption of liquid by the geopolymer specimens increased their mass by $1.3 \%$, compared with an increase in mass of $3.0-3.5 \%$ in the OPC specimens.

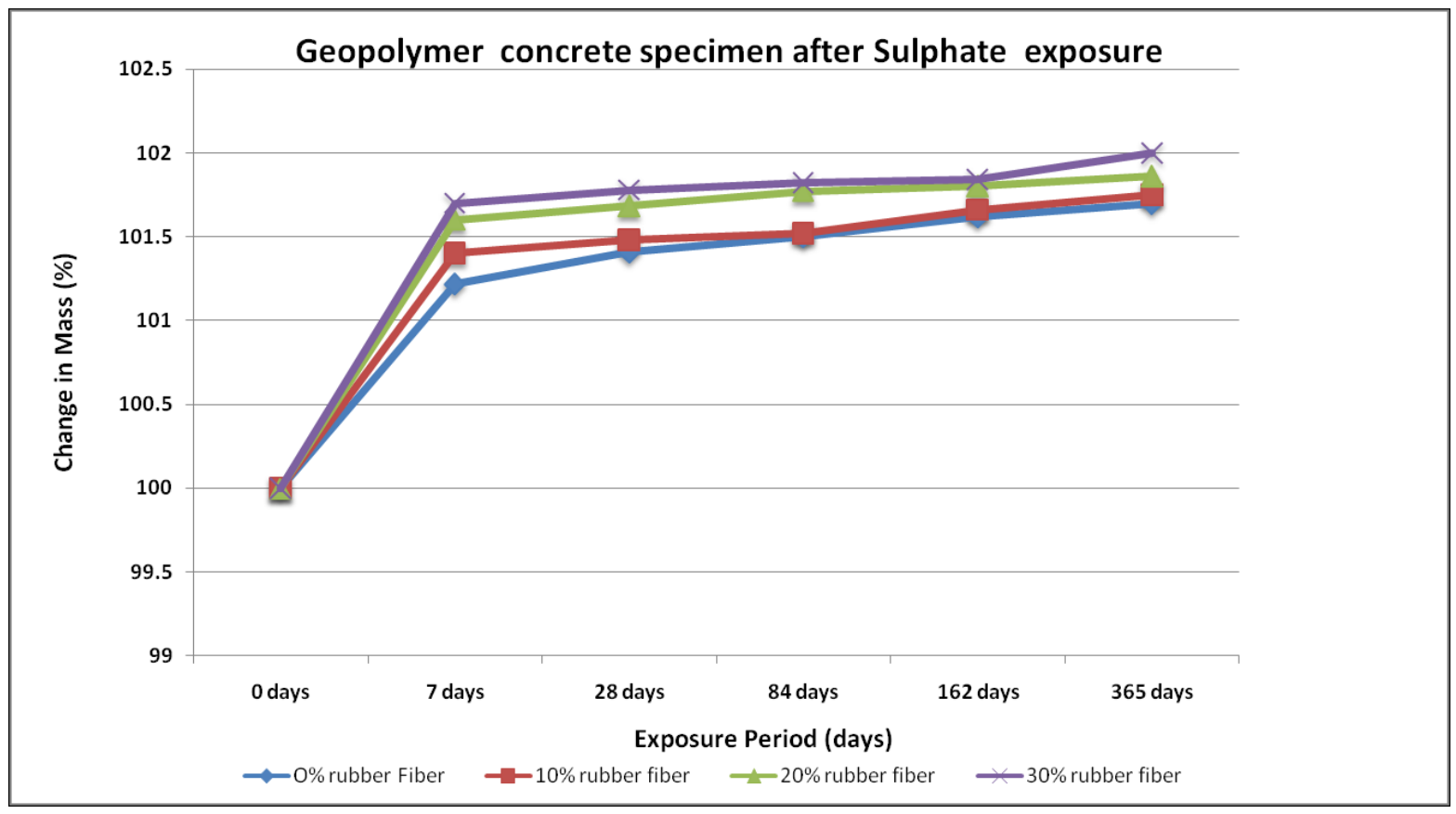

Figure 7. Modification of geopolymer samples mass after exposure to sodium sulphate. 


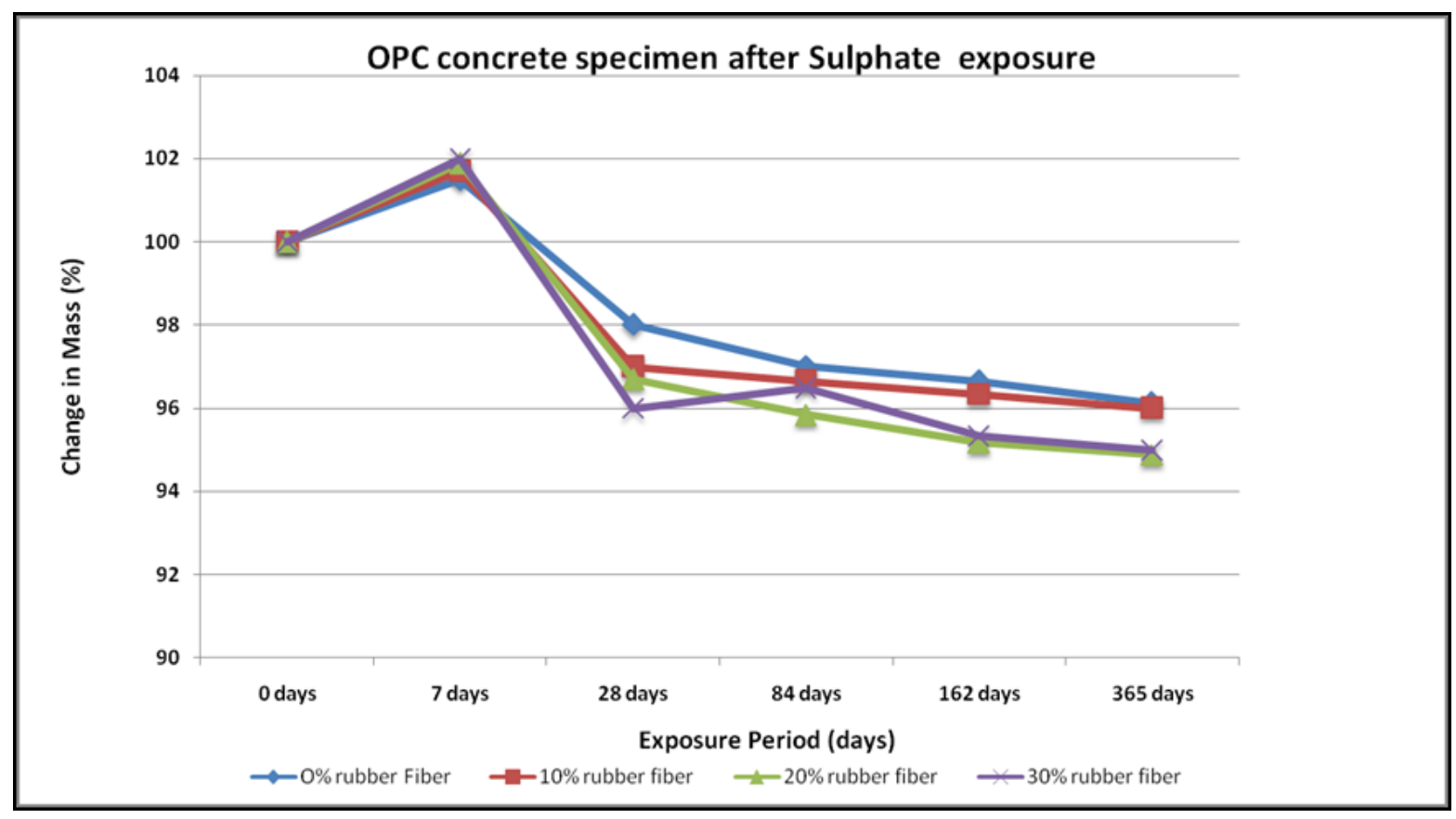

Figure 8. Change in OPC samples mass following exposure to sodium sulphate.

Figures 9 and 10 show changes in the compressive strength of the geopolymer and OPC concrete samples following exposure to sodium sulphate. After exposure, each specimen had compressive strength measured in SSD conditions. In geopolymer samples with exposure, there has been an important shift in compressive strength while in OPC concrete samples, compressive strength has been lowered. Due to the creation of ettringite and extended gypsum, the lower compressive strength in OPC concrete results in cracking, extension, and degradation. In previous studies, similar findings were noted [33-40]. In geopolymer concrete, the hydration method is replaced by the geopolymerisation method, meaning that gypsum and ettringite are usually not formed. The high alkali content improves the resistance of geopolymers against sulphate exposure, as confirmed by previous research [33]. The findings indicate obviously that the geopolymer concrete is superior in resistance to sulphates to OPC concrete.

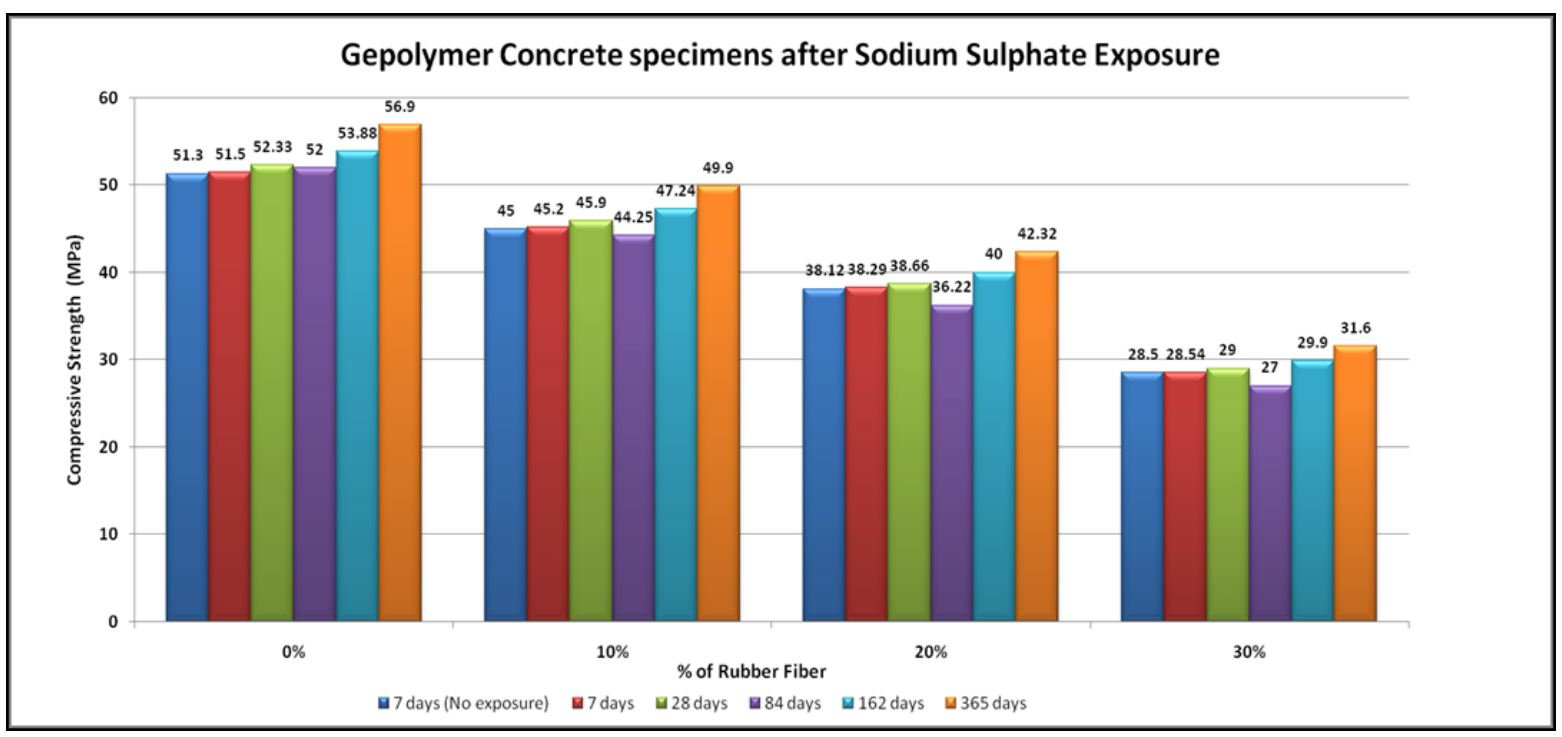

Figure 9. Change in geopolymer concrete compressive strength after exposure to sodium sulphate exposure. 


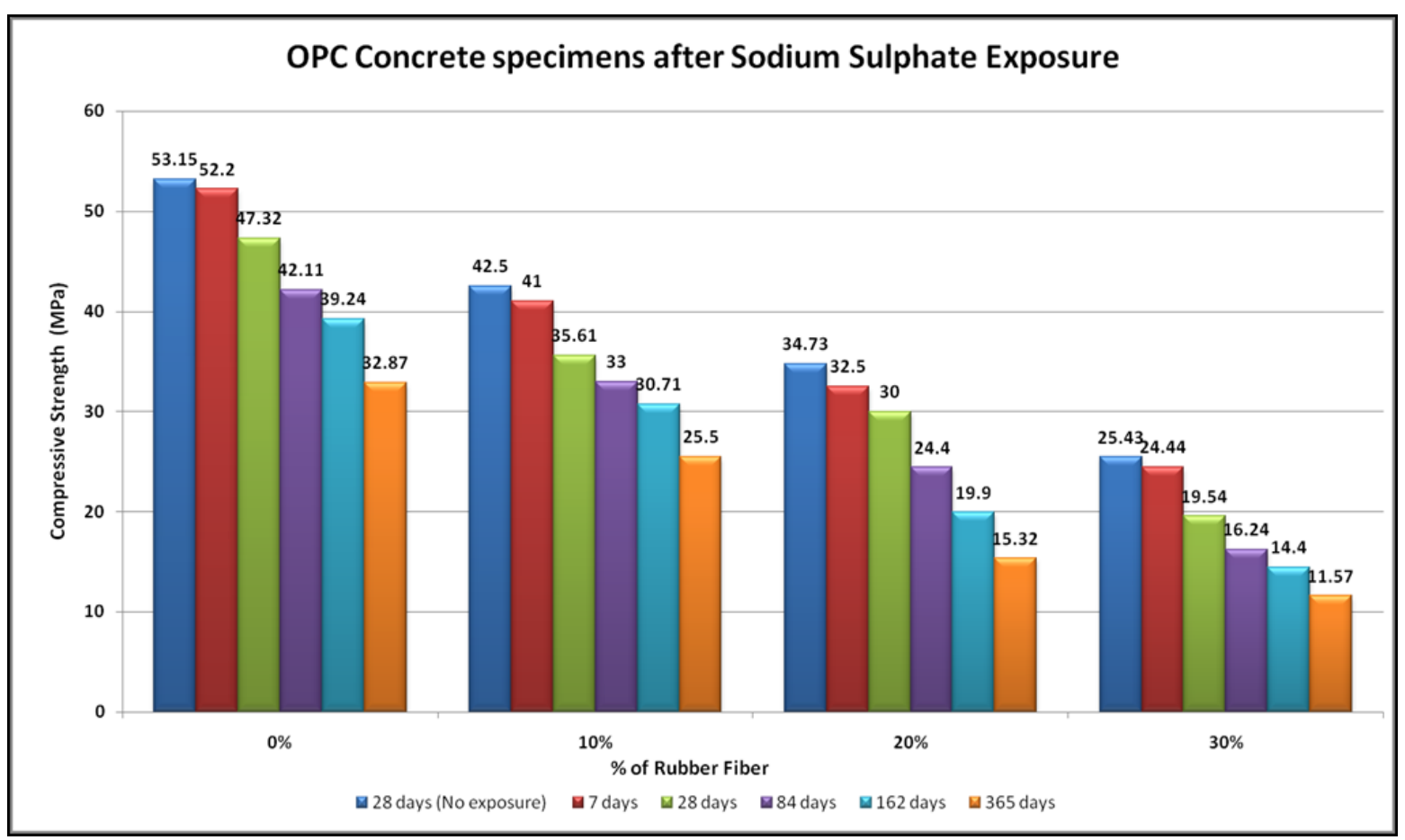

Figure 10. Modification of OPC concrete compressive strength after exposure to sodium sulphate.

\subsection{Acid Resistance}

The acid resistance assessment was observed on the geopolymer concrete as well as OPC concrete specimens by soaking them in 3\%, 5\%, and 10\% concentrations of sulfuric acid for 7, 28, 84, 162, and 365 days. This experiment shows the behaviour, physical appearance, changes in weight, and compression strength changes, after exposure to sulfuric acid, of the geopolymer concrete and OPC concrete.

Figure 11 demonstrates the physical appearance after one year of exposure to geopolymer samples. The specimens of all mixtures undergo erosion after exposure to acid. The damage to the concrete surface increases as the sulfuric acid becomes stronger. OPC concrete samples are more erosive than geopolymer concrete.

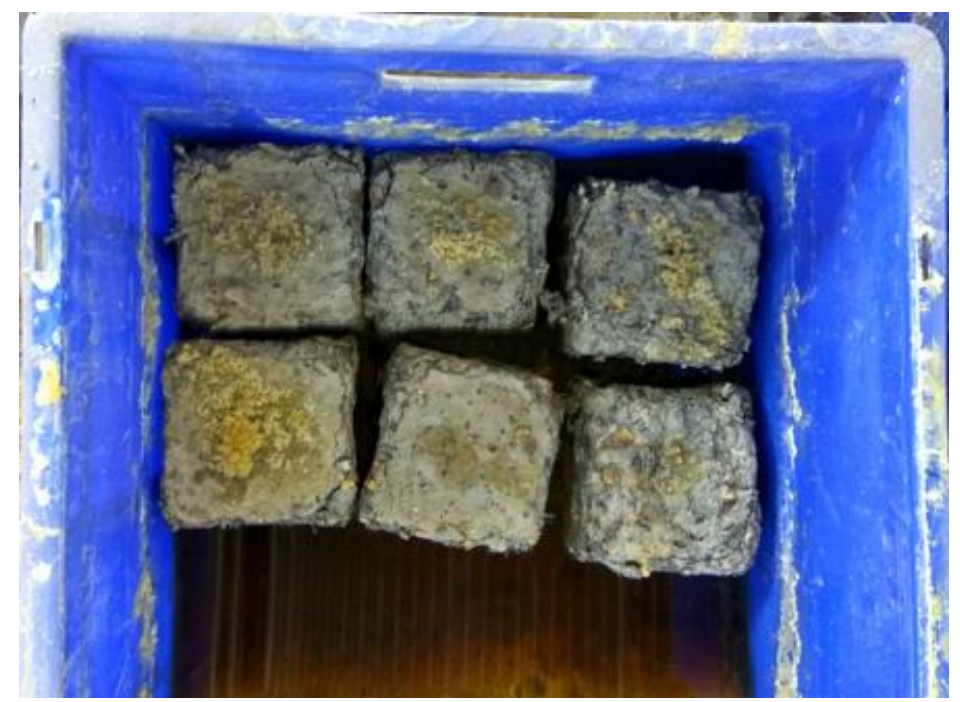

Figure 11. Physical appearances of specimens after sulphuric acid exposure.

Figures 12 and 13 show the change in mass of both types of concrete after 5\% acid exposure for up to 365 days. It could be observed that the geopolymer concrete specimens 
gain some weight during the first week of exposure because they absorb the liquid over this period. From this point on, the mass of all specimens decreases as a result of acid exposure. It is apparent that with the exposure time, the proportion of mass loss rises. In geopolymer concrete, the results for the first week show that the mass of the specimens increased by $0.98-1.15 \%$ for all concentrations, then decreased over the remaining exposure period. In the OPC concrete, the mass of the specimen increased by $1.8-2.5 \%$ in the first week and then decreased. The OPC concrete specimens lost more mass than the geopolymer concrete specimens. This result agrees with previous research [33,41-45].

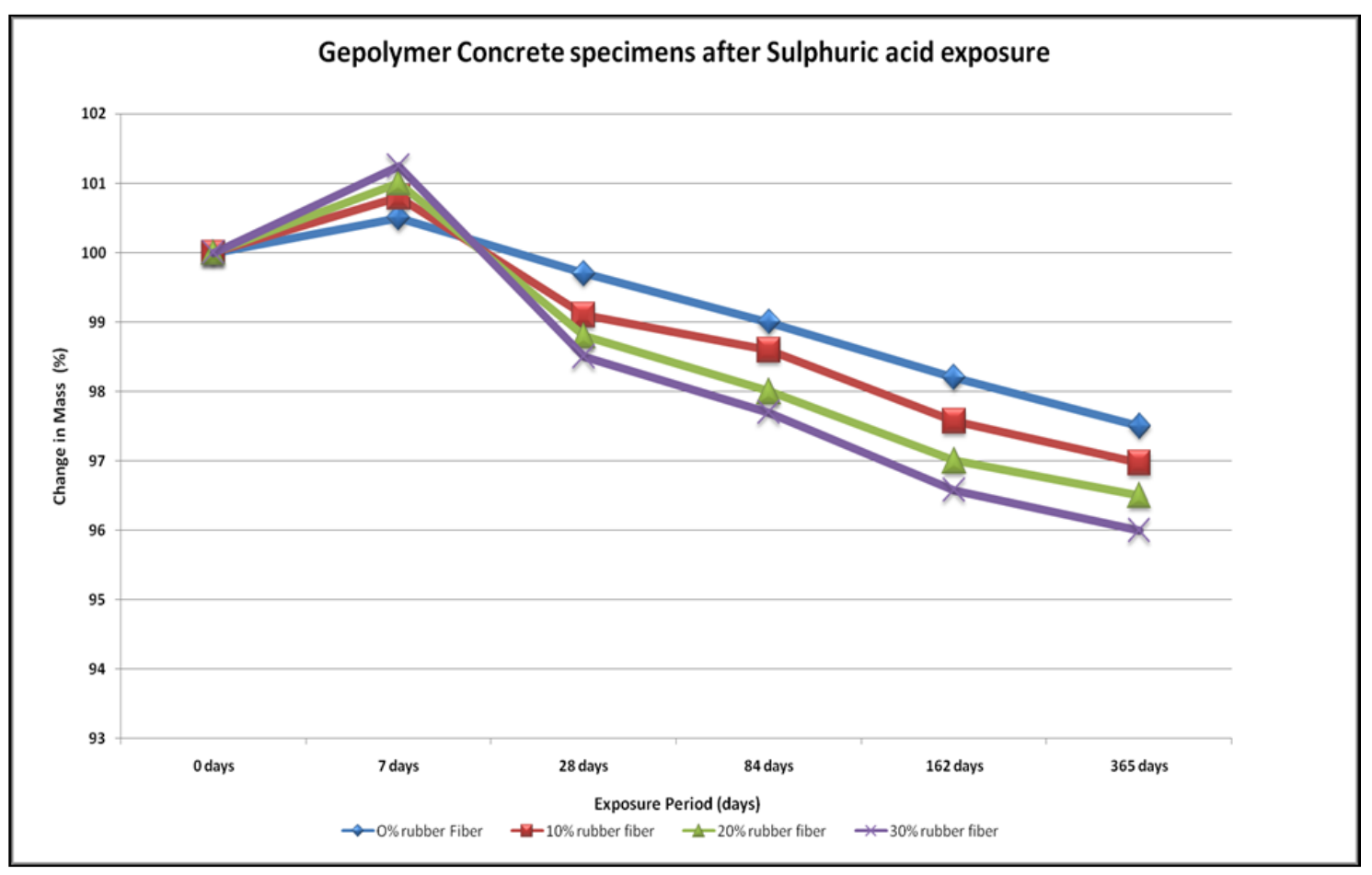

Figure 12. Weight change after sulfuric acid exposure in the geopolymer specimen.

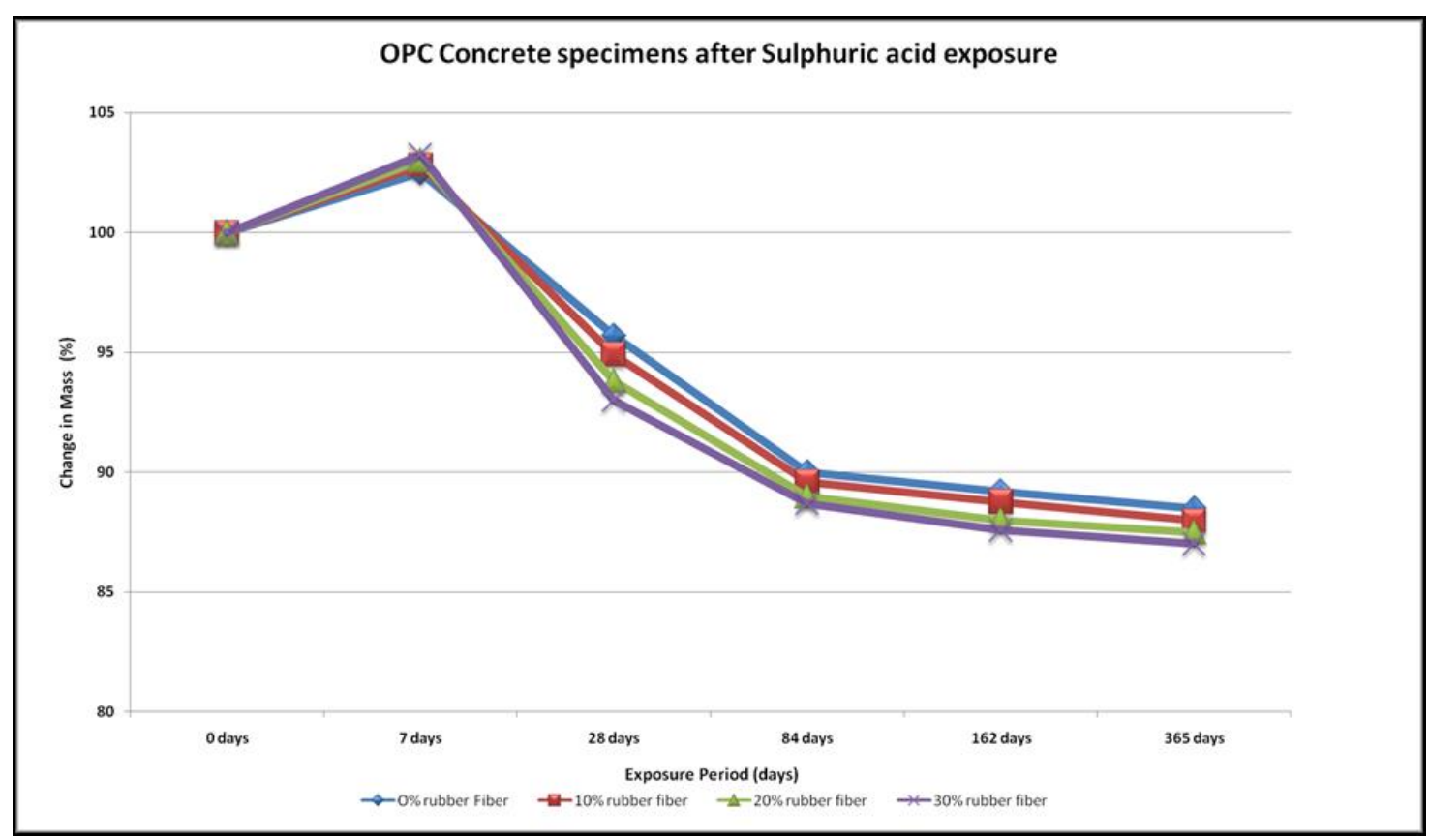

Figure 13. Change in OPC concrete samples mass after exposure to sulfuric acid. 
Figures 14-19, showing changes in geopolymer concrete and OPC concrete strength following each exposure cycle. These findings can be contrasted with the compressive intensity of non-acidic samples.

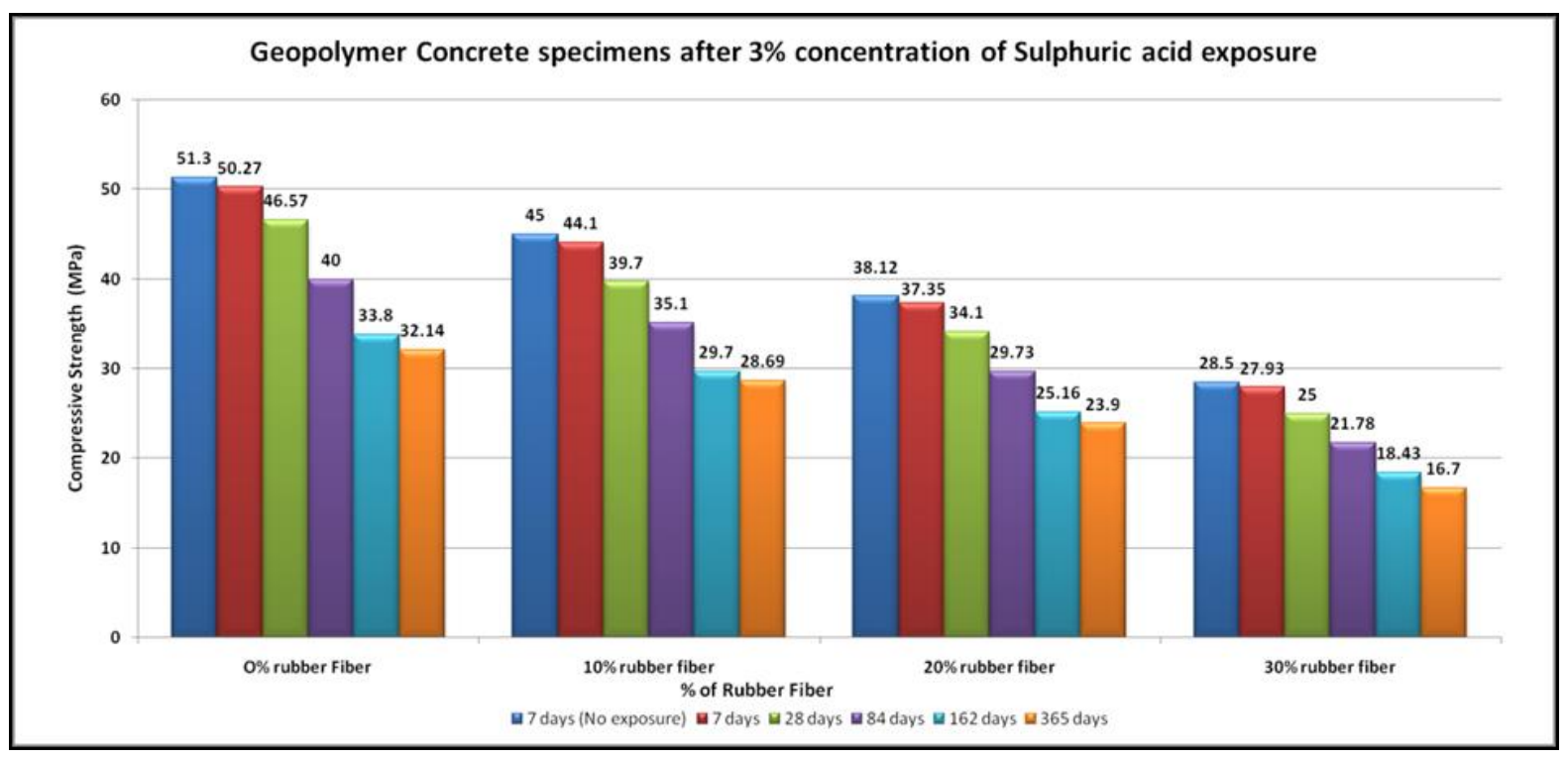

Figure 14. Change in geopolymer compressive strength after exposure to $3 \%$ sulfuric acid.

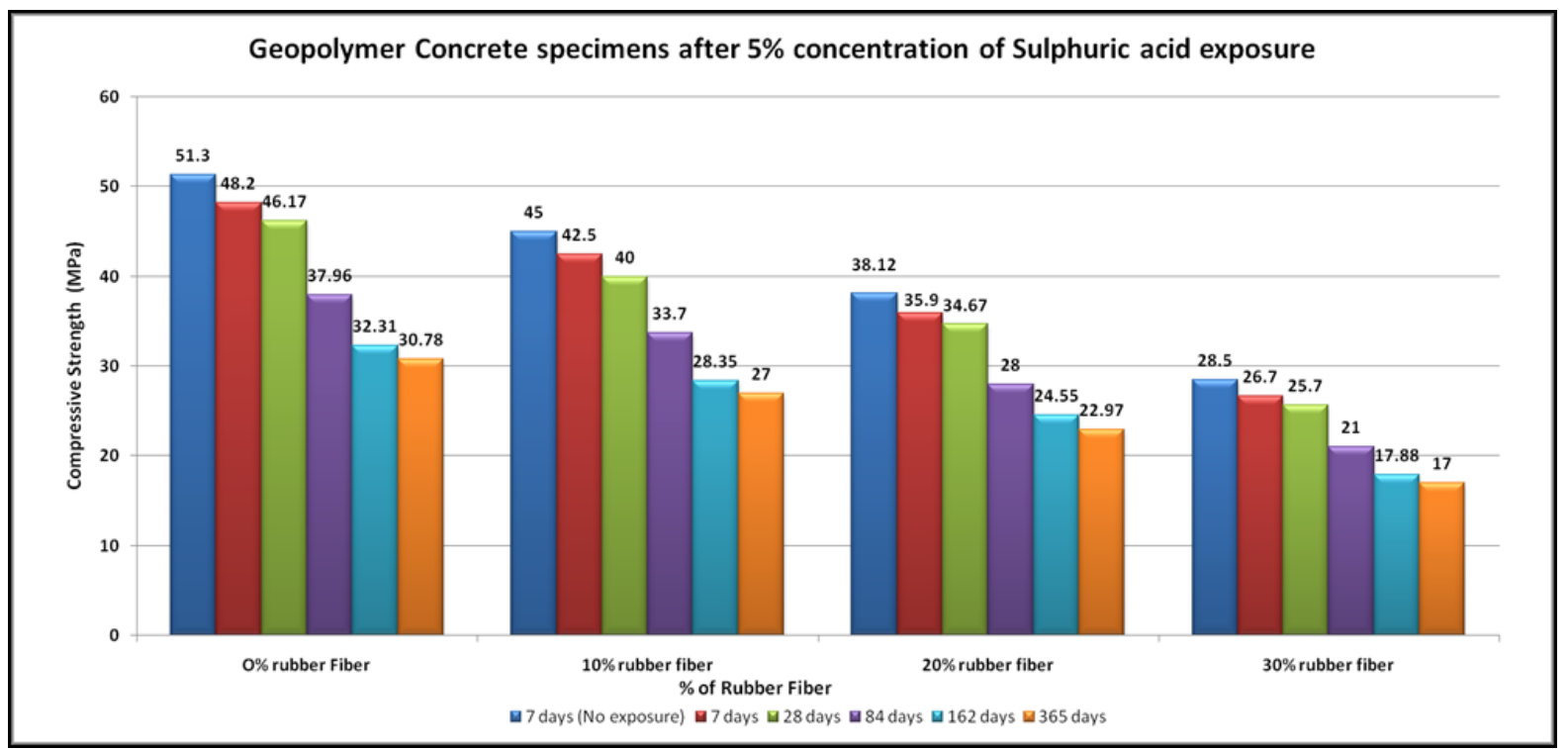

Figure 15. Modification of the geopolymer compressive strength following exposure to $5 \%$ sulfuric acid.

Figures 14-19 show that exposure to sulphuric acid decreases its compressive strength. Compressive strength change relies on the sulfuric acid concentration and exposure duration. Increases in the period of exposure and concentration of sulfuric acid enhance the degradation in compressive strength of all mixes. The rate of reduction of compressive strength is highest following the one-year exposure period. In the control geopolymer concrete, the $3 \%, 5 \%$, and $10 \%$ concentrations of sulfuric acid result in compressive strengths of 32.14,30.78, and 17.65 MPa, respectively, after 365 days, whereas for the control OPC concrete, the respective strengths are 29.23, 26.00, and 13.89 MPa. This demonstrates that the geopolymer concrete is stronger than OPC concrete against sulfuric acid. In geopolymer concrete, the source material contains relatively little calcium, which is the major factor in increasing resistance against acid $[33,43,44]$. In all mixes, it was found that higher 
concentrations of sulfuric acid result in greater deterioration, resulting in greater strength loss. In the geopolymer specimens, this deterioration is due to the formation of zeolite and the depolymerization of alumino-silicate. Similar results have been confirmed by previous research $[33,44]$. These results also prove that geopolymer and OPC concrete containing rubber fibres enhance the concrete porosity, which causes a greater reduction in compressive strength.

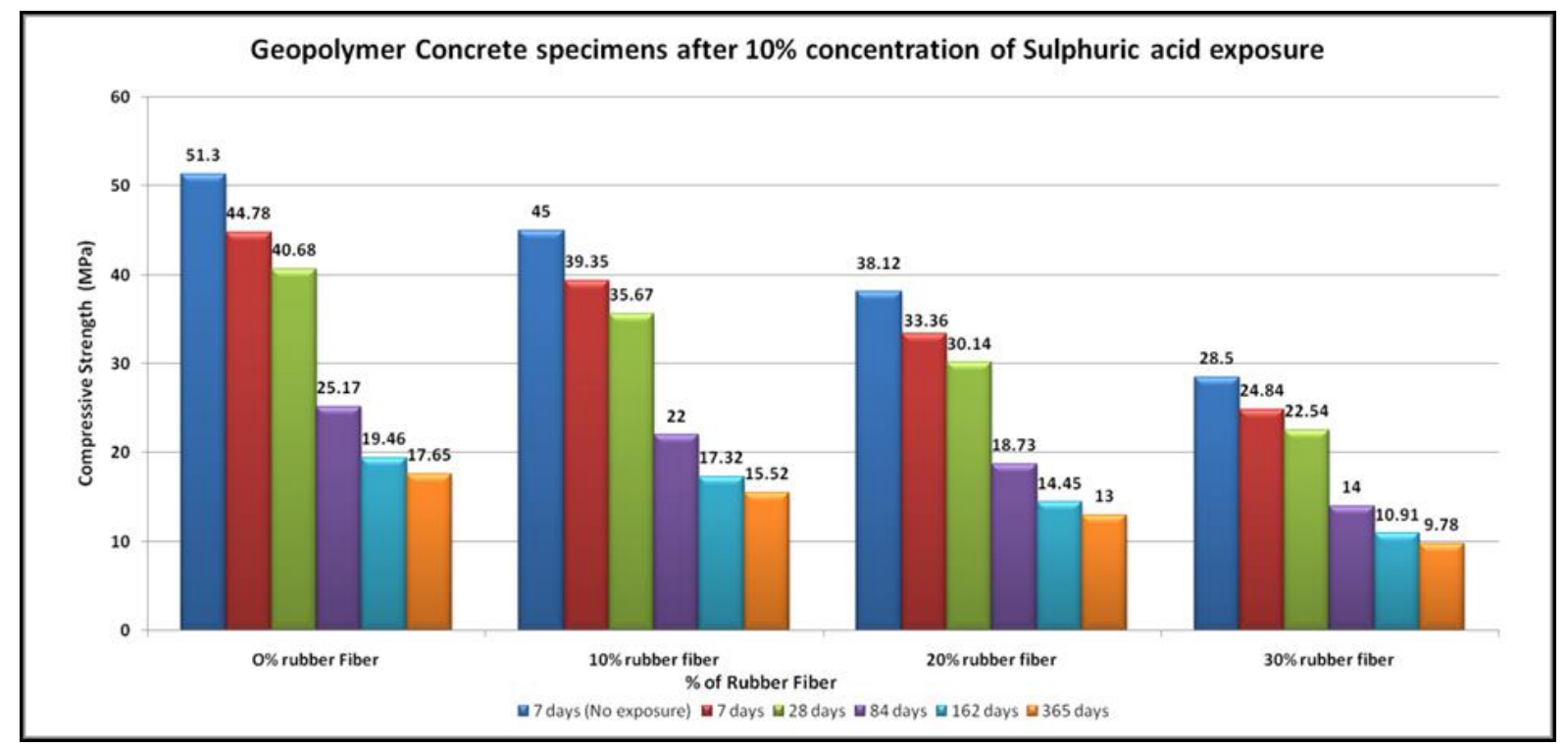

Figure 16. Change in geopolymer compressive strength following $10 \%$ sulfuric acid exposure.

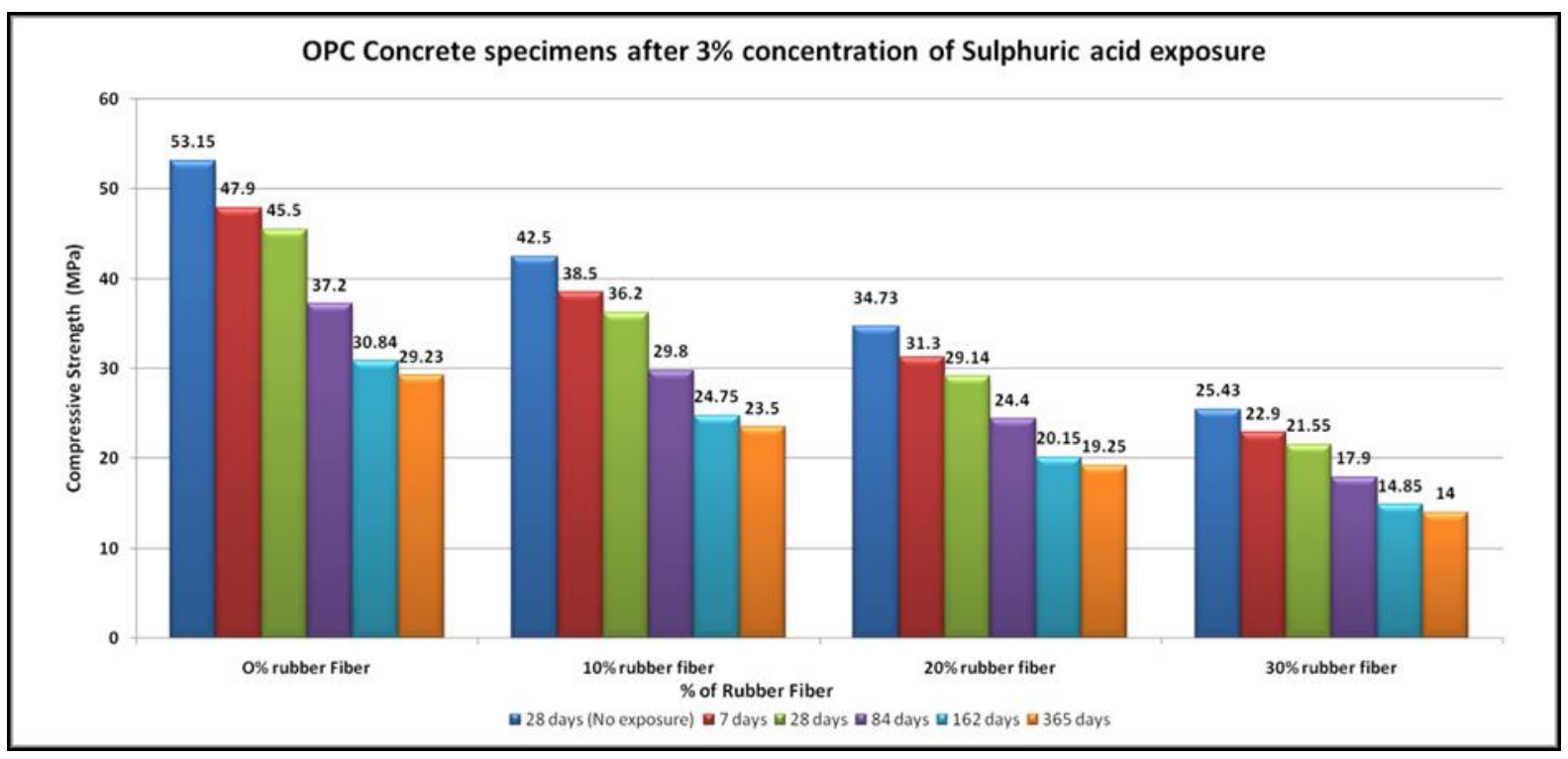

Figure 17. Compressive resistance change in OPC samples after 3\% sulfuric acid exposure. 


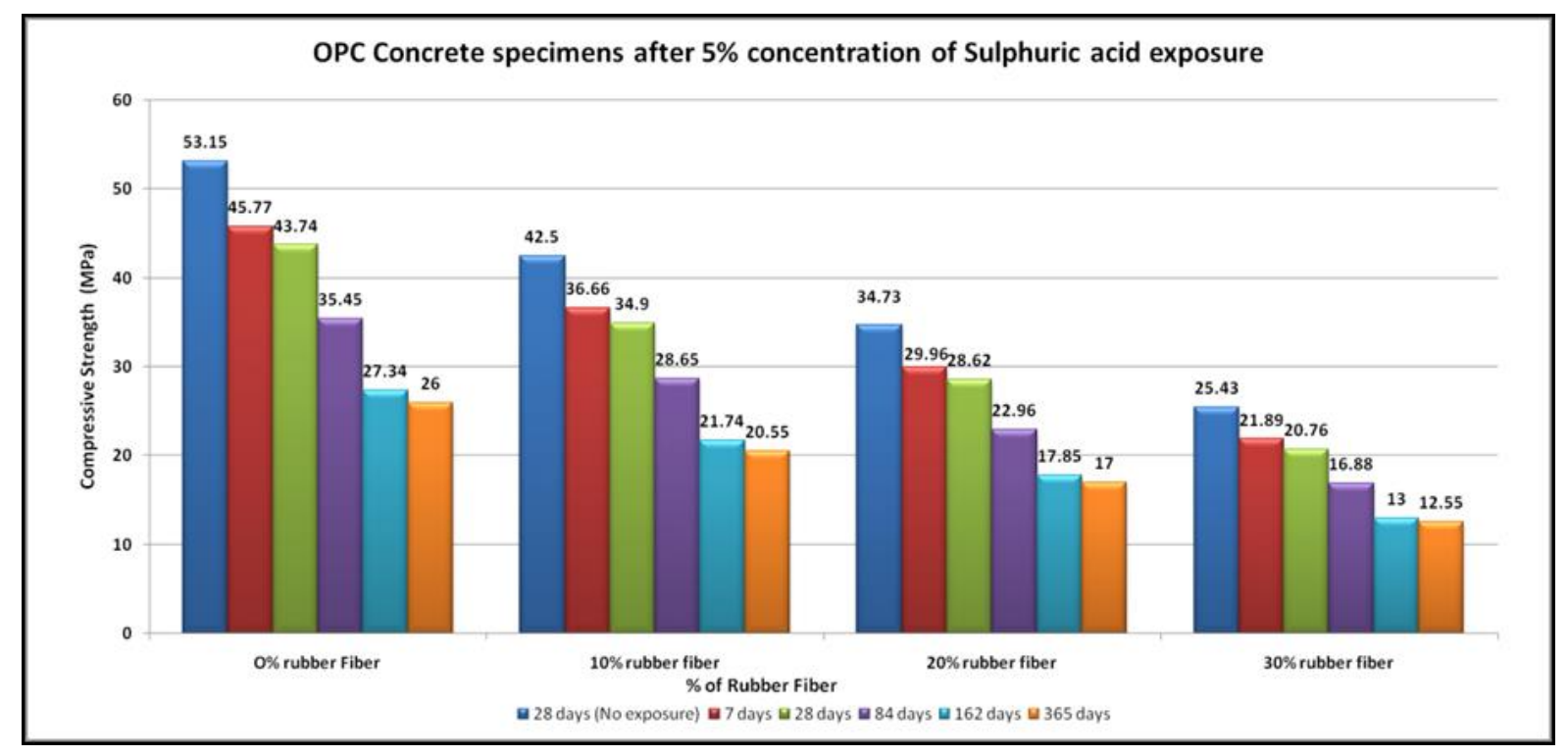

Figure 18. Modification of OPC compression strength after 5\% sulfuric acid exposure.

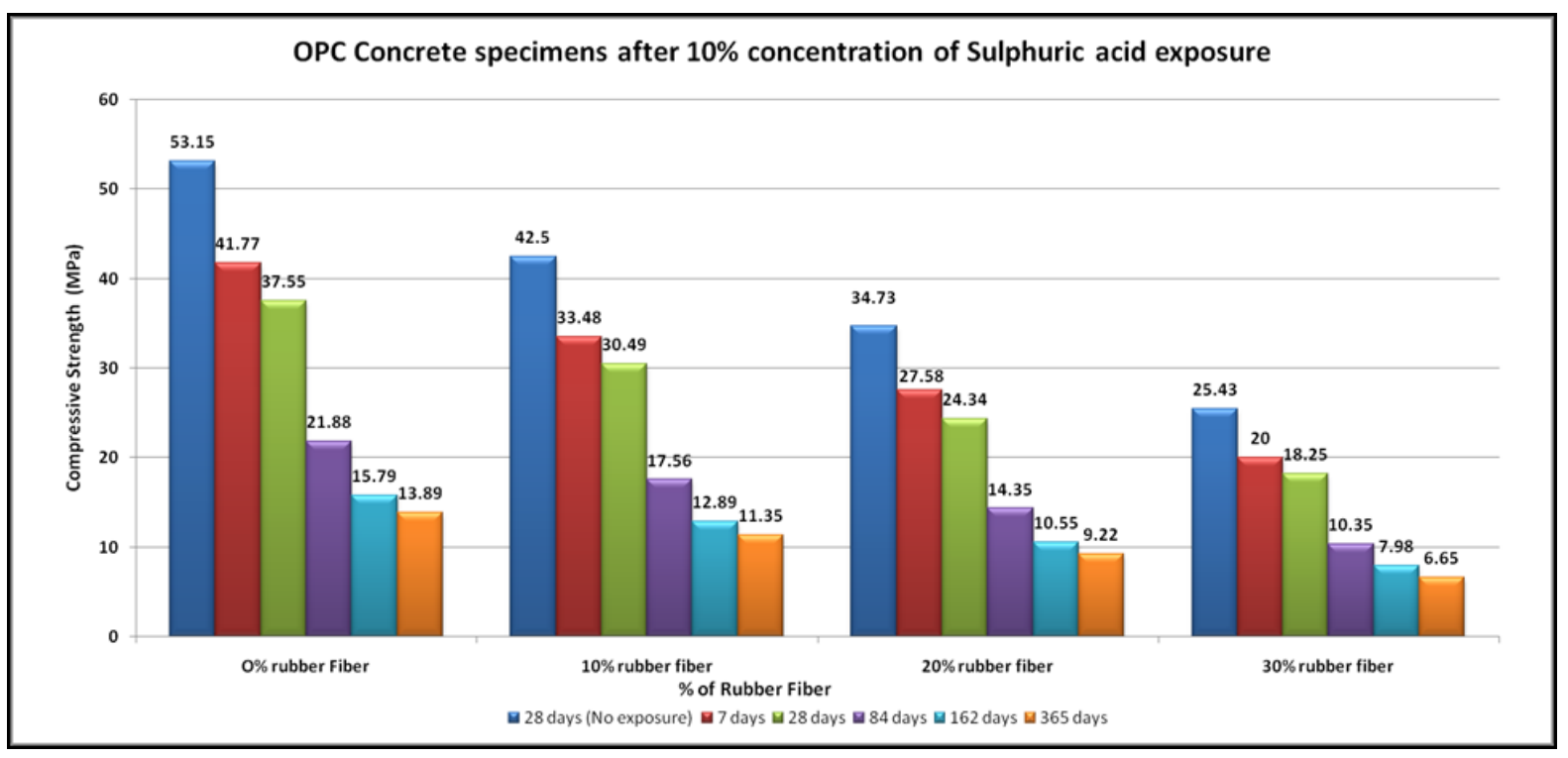

Figure 19. Compressive strength changes for the OPC samples after $10 \%$ sulfuric acid exposure.

\subsection{Chloride Diffusion}

For geopolymer and OPC concrete samples, a continuous state chloride ion migration experiment was conducted, and the chloride diffusion coefficients are listed in Figure 20. The geopolymer concrete has reduced diffusion coefficients of chloride compared to OPC concrete from this figure. The chloride diffusion coefficients increase with the rubber fibre content in both types of concrete. The minimum chlorine diffusion coefficients for geopolymer concrete and OPC concrete are $1.0 \times 10^{-12}$ and $1.5 \times 10^{-12}$, respectively, and the maximum chloride diffusion coefficients are $1.2 \times 10^{-12}$ and $1.7 \times 10^{-12}$, respectively. These values are comparable to the values of earlier research [45].

\subsection{Corrosion Resistance}

\subsubsection{Macrocell Current Measurements}

A 100-Ohm resistance was used to measure the macrocell current according to ASTM G109 [42]. The favourable macrocell current shows that the corrosion is ongoing. To guarantee adequate corrosion, a minimum of $10 \mu \mathrm{A}$ is regarded. Figure 21 demonstrates 
that macrocellular current was less than $10 \mu \mathrm{A}$ in the case of both control and rubberized geopolymer concrete, up to 9 months, whereas, in the 10,11, and 12th month all mixes received more than $10 \mu \mathrm{A}$ macrocell currents. Figures 21 and 22 show the variability of macrocell current overtime for geopolymer concrete and OPC concrete. The macrocell current for rubberized concrete was more than that for the control concrete at all ages.

The current in OPC concrete exceeded $10 \mu \mathrm{A}$ in all mixtures from the 8th month to the 12th month. For geopolymer concrete, the highest anode current for the control mixture was $11.2 \mu \mathrm{A}, 13.4 \mu \mathrm{A}, 17.1 \mu \mathrm{A}$, and $19.3 \mu \mathrm{A}$ for the 12 th month, while the peak current was measured at $15.3 \mu \mathrm{A}, 18.9 \mu \mathrm{A}, 15.8 \mu \mathrm{A}$, and $22.1 \mathrm{~mA}$ for OPC concrete. The above findings demonstrate that the incorporation of rubber waste fibres improve the likelihood of early corrosion initiation in both kinds of concrete.

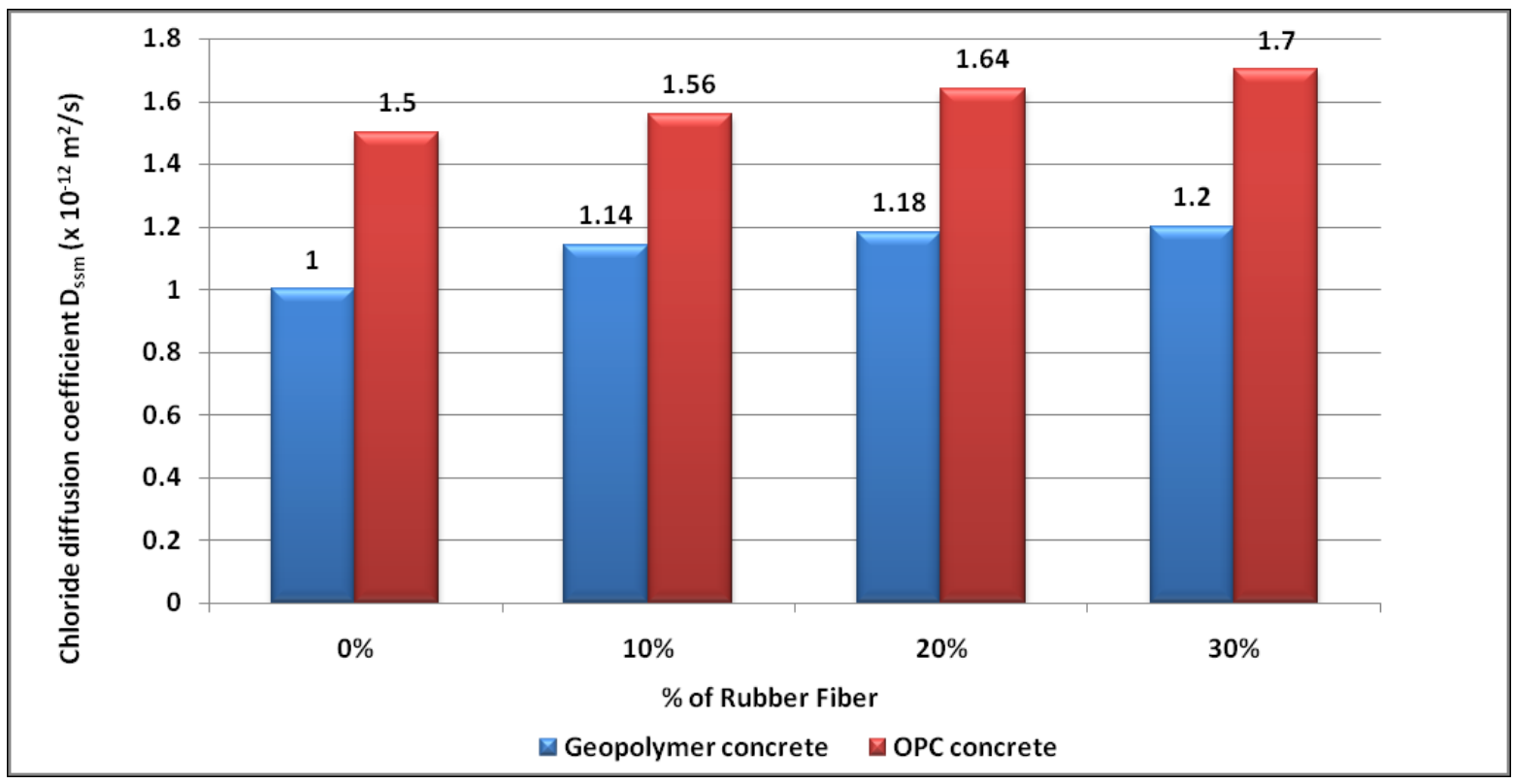

Figure 20. Chloride diffusion coefficient of geopolymer and OPC concrete.

\section{Geopolymer Concrete}

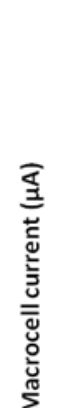

Exposure period (months)

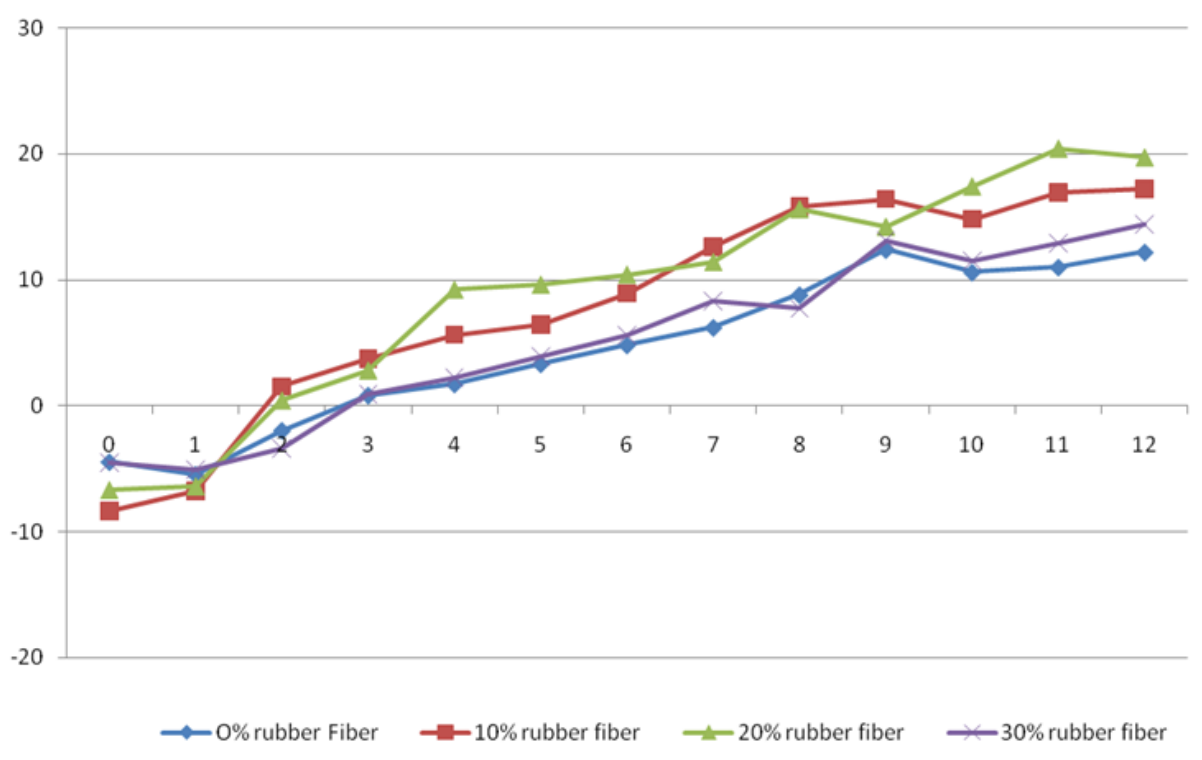

Figure 21. Geopolymer concrete macrocell current. 


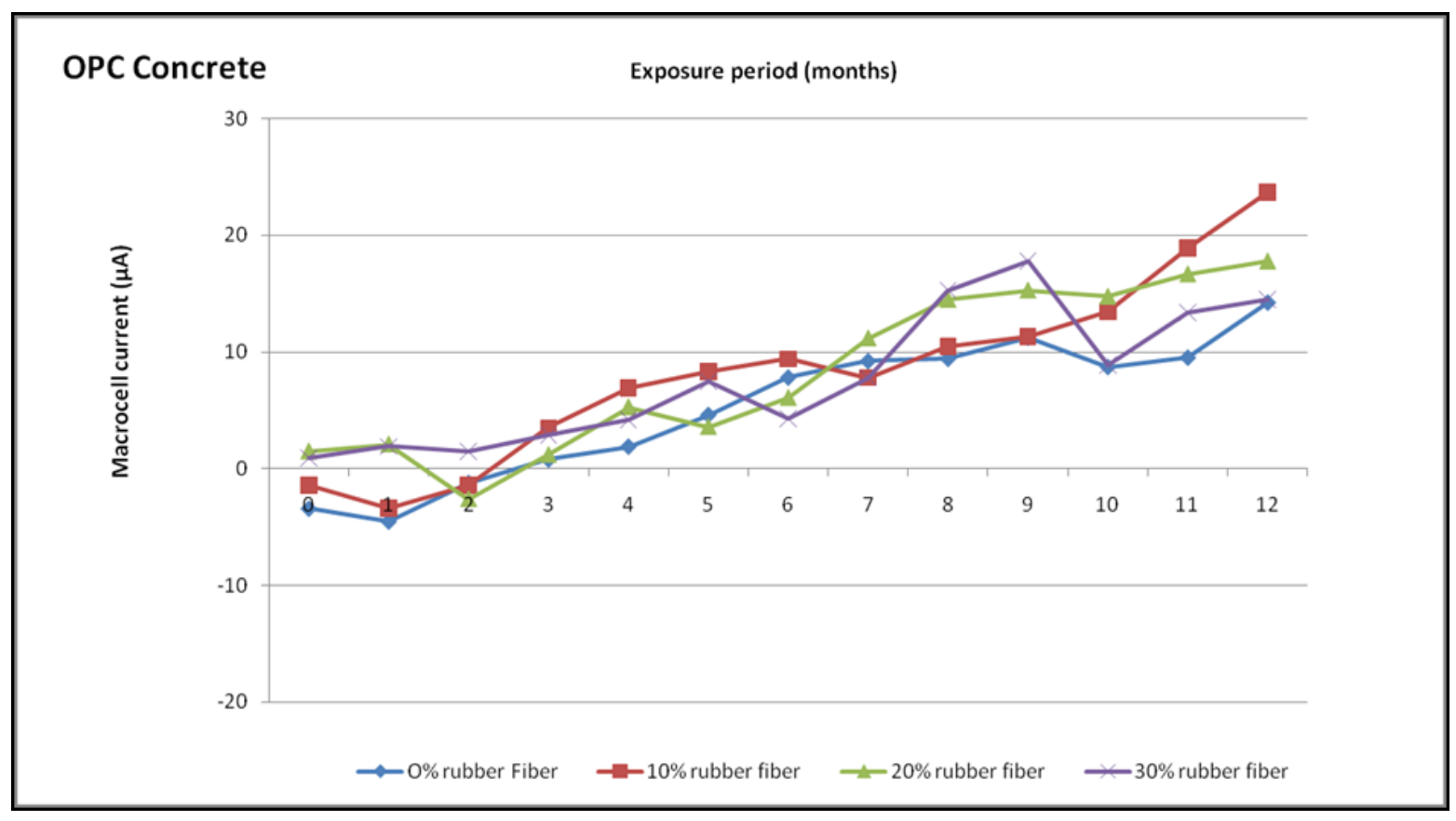

Figure 22. OPC concrete Macrocell Current.

\subsubsection{Half-Cell Potential Measurements}

The half cell potential was evaluated between the top bar and a reference electrode following ASTM C876 [28]. Figures 23 and 24 show the outcomes of half-cell potential measurements for geopolymer and OPC concrete. According to ASTM standards, the likelihood of corrosion in reinforcement steel bars is more than $90 \%$ where potentials are more negative than $-350 \mathrm{mV}$. The potentials for geopolymer concrete were less negative than $-350 \mathrm{mV}$ up to 9 months, compared to $-350 \mathrm{mV}$ for the OPC concrete up to 8 months (See Figures 23 and 24).

The variance of geopolymer and OPC concrete half cell potential are shown in Figure 24. The half-cell potential of rubber fibre waste-concrete has been higher than that of the control mix at different ages. In the case of geopolymer concrete, a more negative than $-350 \mathrm{mV}$ was reported from the 10th month to 12th month, whilst in the 9th month to 12th month, OPC concrete potential became more negative than $-350 \mathrm{mV}$. The maximum potential was measured as $-360 \mathrm{mV},-400 \mathrm{mV},-420$, and $-460 \mathrm{mV}$ for geopolymer concrete at 12 months while the supreme potential for OPC concrete at 12 months was obtained as $-400 \mathrm{mV},-455 \mathrm{mV},-482 \mathrm{mV}$, and $-500 \mathrm{mV}$. From the foregoing outcomes, the geopolymer concrete reduces the likelihood of corrosion initiation in comparison to OPC concrete.

\subsection{Drying Shrinkage}

The drying shrinkage with time is shown in Figures 25 and 26 for geopolymer concrete and OPC concrete. From the figure, it could be observed that geopolymer concrete undergoes a low drying shrinkage when compared with OPC concrete. The low drying shrink connected with its thin pores results in low diffusiveness and a significant reduction in the drying shrinkage rate. Water is expelled during the geopolymerisation phase and less water is found in geopolymer concrete micropores. This is caused by low drying shrinkage. Due to moisture motion from the atmosphere to the concrete, shrinking stress fluctuates over time and vice versa, which results in reversible shrinking and concrete swelling. The drying shrinkage can be observed as the content of the rubber fibre and time are increased. The boost in porosity owing to the inclusion of rubber particles in concrete. 


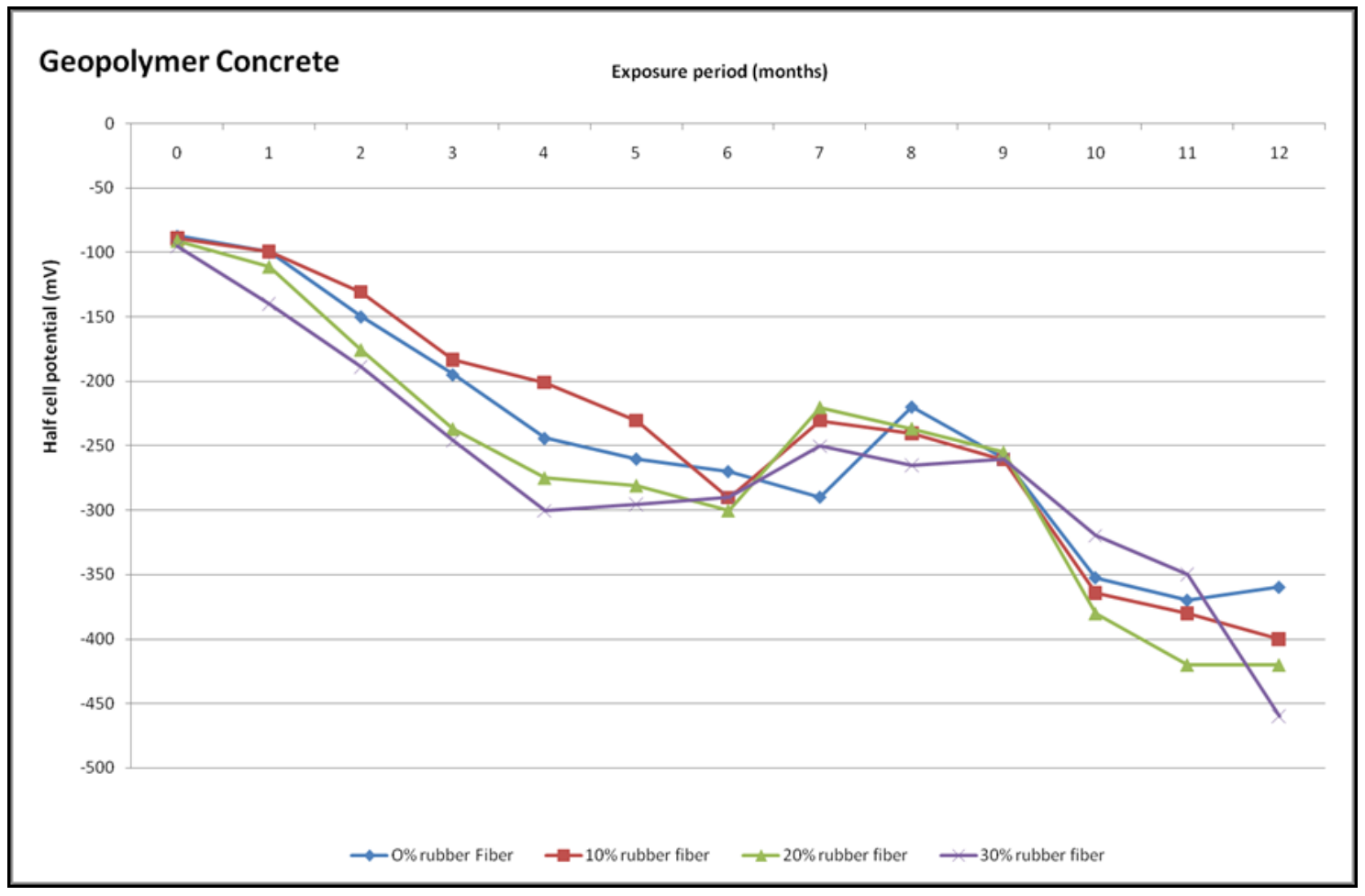

Figure 23. Half-cell potential measurement of geopolymer concrete.

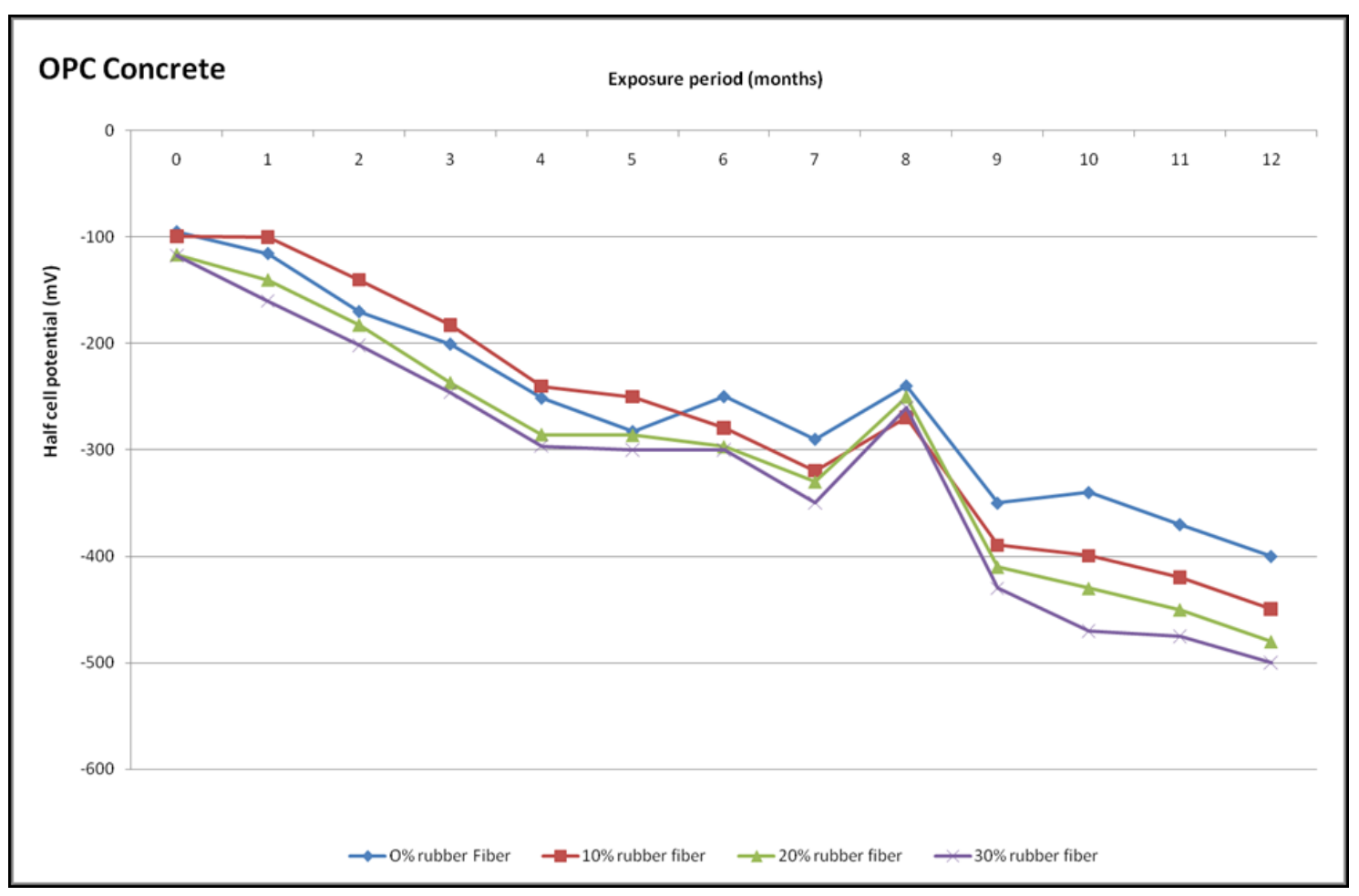

Figure 24. Half-cell potential measurement of OPC concrete.

\subsection{Carbonation Resistance}

The carbonation depth measured for geopolymer and OPC concrete is shown in Figures 27 and 28 for 14-, 21-, 28-, 35-, 42-, 56-, and 90-days duration (5\% $\mathrm{CO}_{2}$ exposure). The carbonation depth can be found to be increased by increasing the duration of $\mathrm{CO}_{2}$ exposure and replacement of all mixes. The current study shows that carbonation depth 
was less than the minimum cover required for the concrete $(15 \mathrm{~mm})$ at the immense substitution level (30\%) and elevated $\mathrm{CO}_{2}$ levels ( $5 \%$ for 90 days). The carbonation depth reduced with increased rubber content for any replacement of the fine aggregate by rubber fibre. As previously noted in this study, an increase in carbon depth could be caused by a rise in water intake and water permeability. For geopolymer concrete with a $30 \%$ fine aggregate replacement level, the maximum carbonation depth of $8.0 \mathrm{~mm}$ had to be observed, whereas for OPC concrete, with an exposure of 90 days, at the same replacement level the carbonation depth was $9.0 \mathrm{~mm}$.

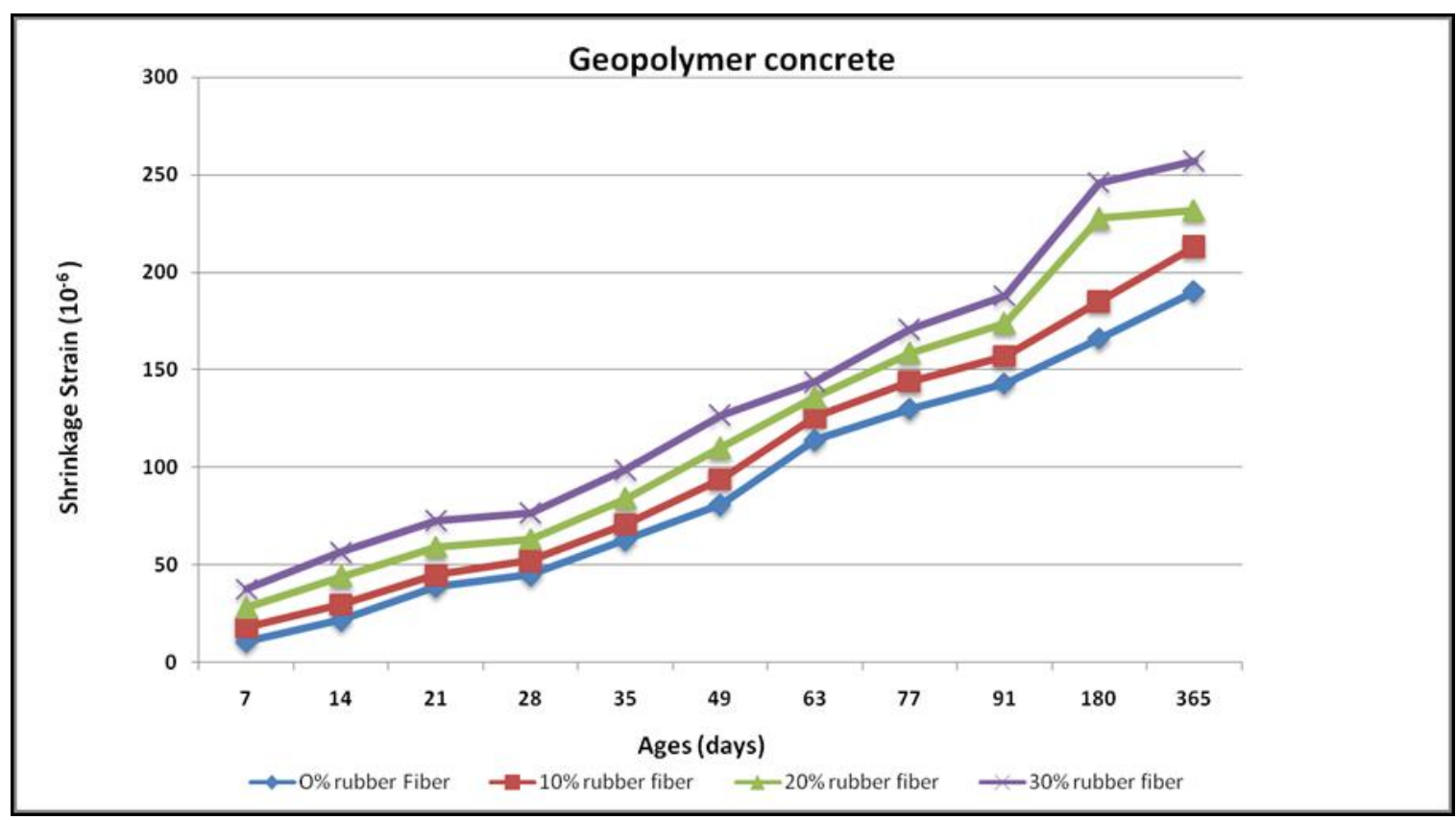

Figure 25. Drying shrinkage of geopolymer concrete specimen.

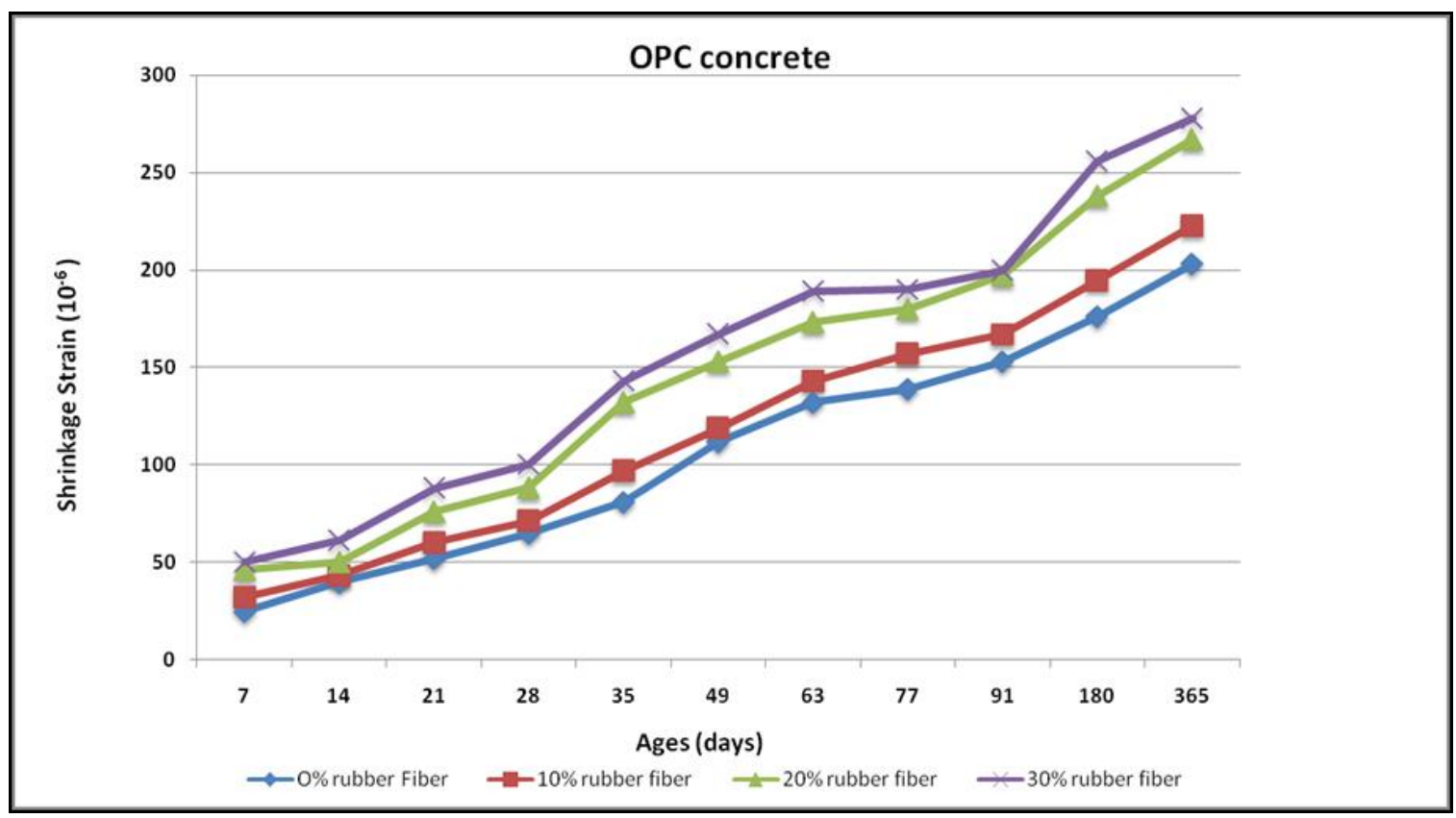

Figure 26. Drying shrinkage of OPC concrete specimen. 


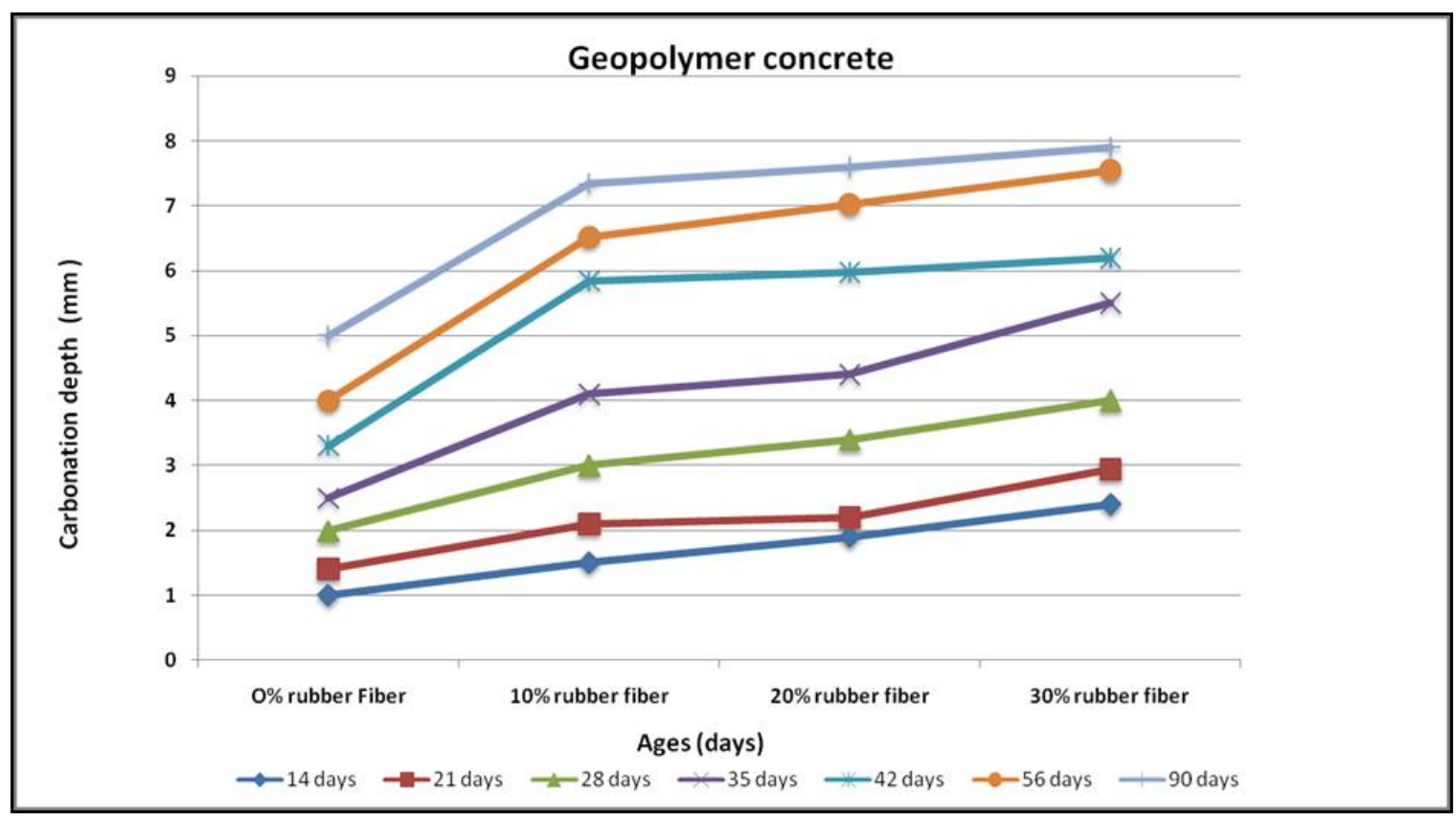

Figure 27. Carbonation depth of geopolymer concrete specimen.

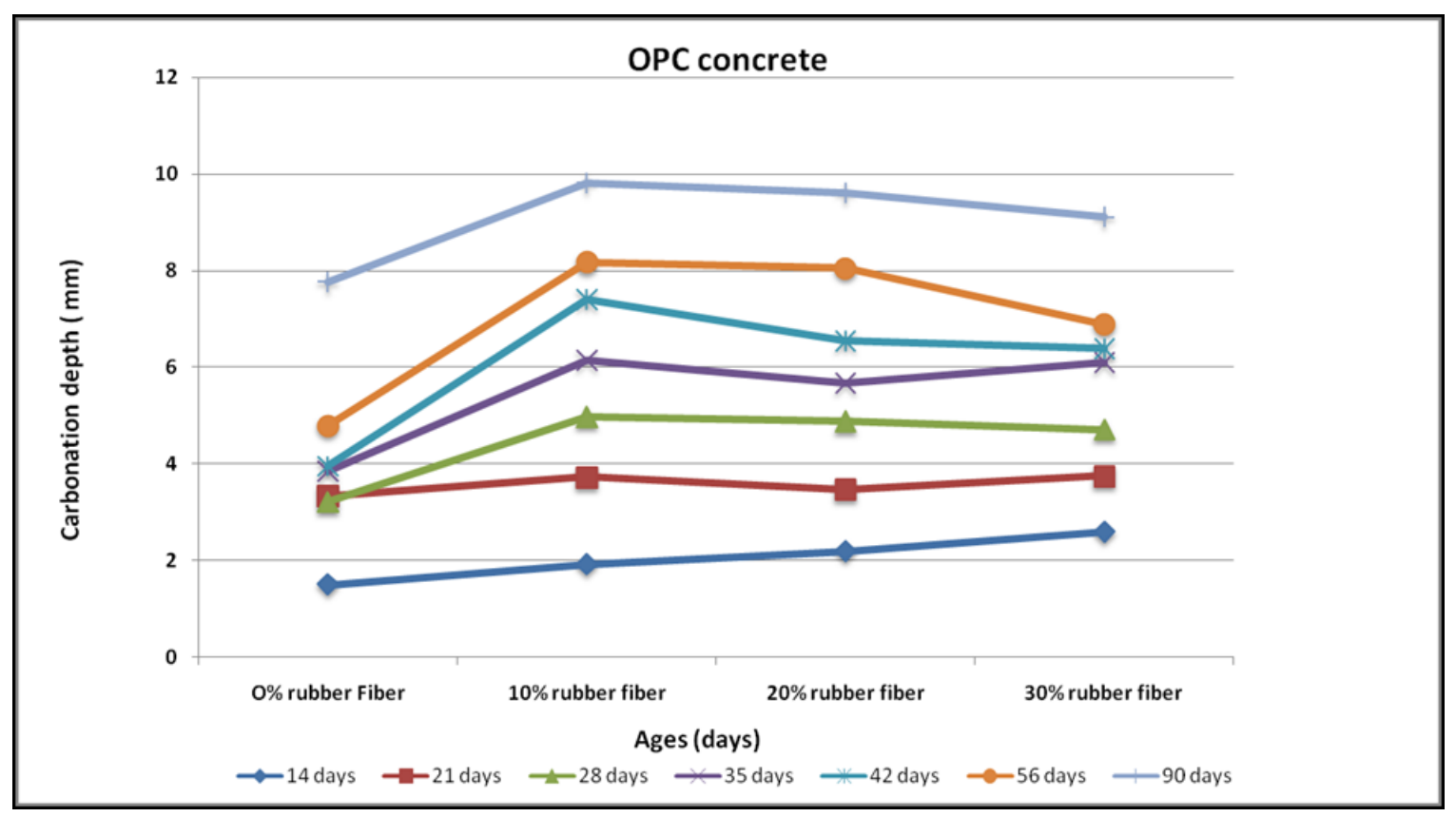

Figure 28. Carbonation depth of OPC concrete specimen.

\subsection{Salt Resistance}

Geopolymer concrete and OPC concrete have been tested for salt resistance. The test was performed by soaking the specimen in $5 \% \mathrm{NaCl}$ (Sodium chloride) solution. After exposure for $7,28,84,162$, and 365 days, salt resistance was assessed based on a shift in compression strength. Geopolymer concrete and OPC concrete compressive resistance are demonstrated in Figures 29 and 30, respectively, following sodium chloride exposures. The compressive strength of specimens was taken under saturated surface dry conditions after exposure and the results were compared with the specimens with no exposure. The compressive strength of geopolymer concrete on salty solution exposures was not significantly changed. However, the compressive strength of the rubberized geopolymer 
cement was somewhat reduced following the exposure of salt with $10 \%$ substitution. There was a significant reduction in the compressive strength on exposure to a salty solution for the control OPC concrete as well as the rubberized concrete. The results clearly show the excellent resistance of geopolymer concrete (both control as well as rubberized) against the OPC concrete (both rubberized as well as geopolymer).

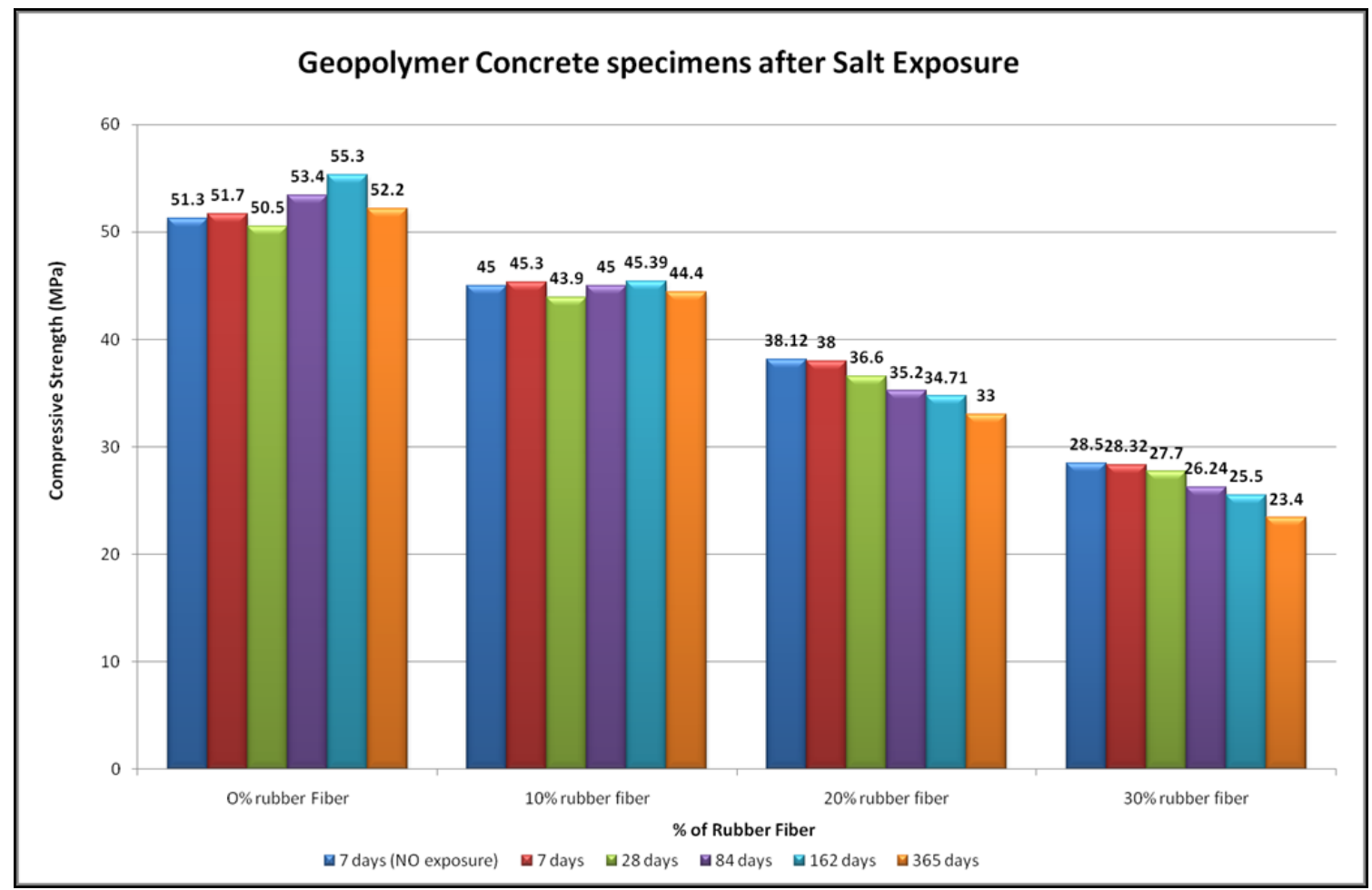

Figure 29. Salt Resistance of geopolymer concrete specimen.

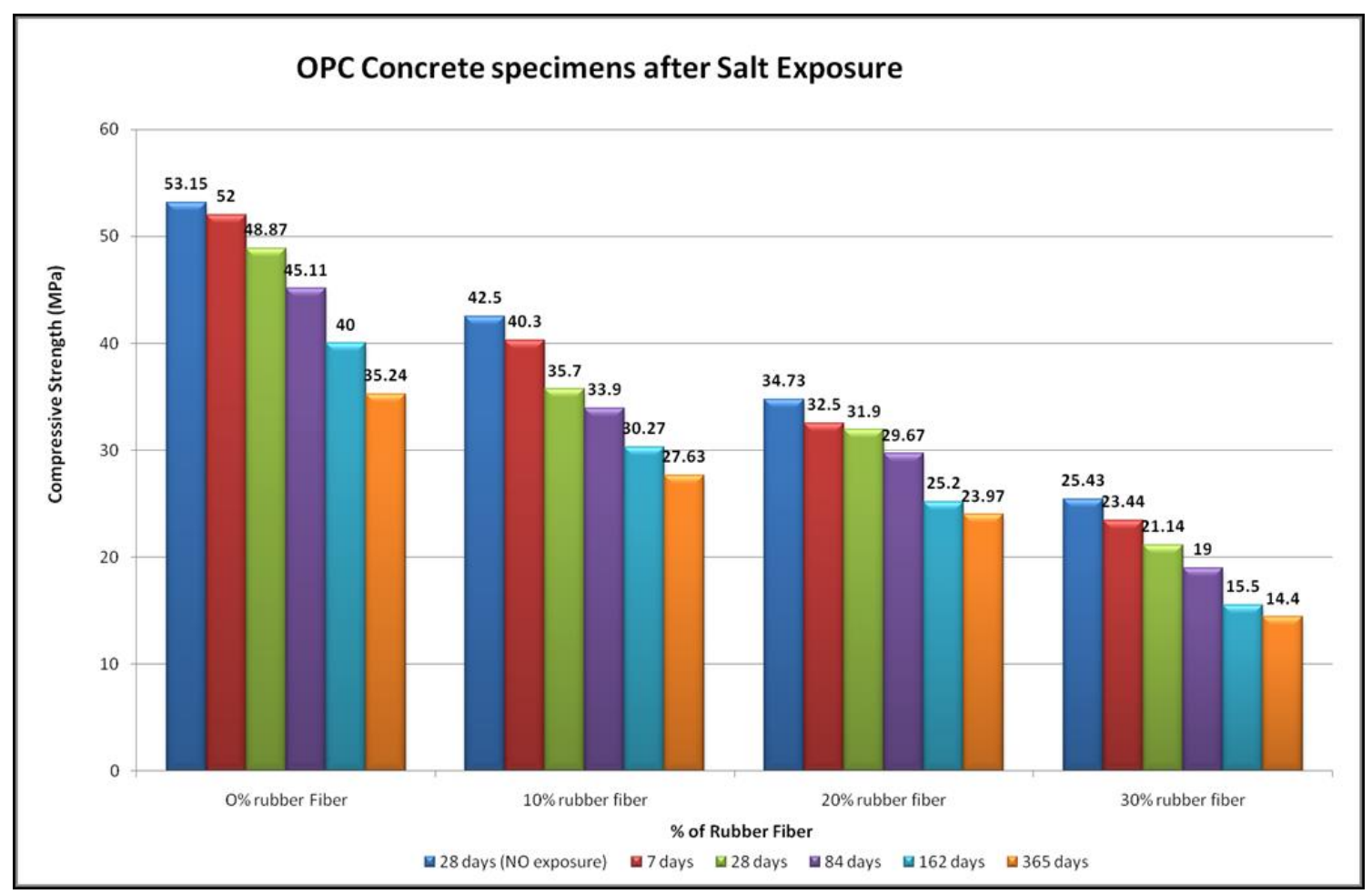

Figure 30. Salt Resistance of OPC concrete specimen. 


\section{Conclusions}

The following conclusions can be taken from the outcomes reported in this study:

1. The depth of water penetration rises with enhanced rubber fibre. In geopolymer concrete, the water penetration depth is smaller than in OPC concrete. The rise of the depth of penetration can be explained by the increased porosity of concrete, as is apparent at greater rubber fibre substitution concentrations.

2. No physical modifications in the geopolymer samples were noted after exposure to sodium sulphate for up to a year. These specimens did not exhibit any change in shape, and no cracking or spalling. In contrast, the OPC concrete specimen had expanded and suffered from frequent random cracking. After exposure in the geopolymer samples, there were substantial changes in compressive strength, whereas OPC concrete samples showed lower compressive strength.

3. The specimens of all mixtures undergo erosion after exposure to acid. The damage to the concrete surface increases as the sulfuric acid becomes stronger. It was found that higher concentrations of sulfuric acid result in greater deterioration, resulting in greater loss of strength.

4. Geopolymer concrete has greater reduced diffusion coefficients of chloride than OPC concrete. The chloride diffusion coefficients increase with the rubber fibre content in both types of concrete.

5. The macrocell current was greater than that for the control concrete at all ages for the rubberized concrete mixtures. The current for OPC concrete used is $10 \mu \mathrm{A}$ for mixes at 8 months to 12 months. The incorporation of rubber waste fibre improves the likelihood of corrosion in both kinds of concrete at an early stage.

6. The half-cell potential for the geopolymer and OPC concrete with waste fibres was greater than for the control geopolymer and OPC concrete. There recorded more negative than $-350 \mathrm{mV}$ in context to rubberized geopolymer concrete from the 10th month to the 12th month, while in the 9th month to the 12th month rubberized OPC concrete potential was higher than $-350 \mathrm{mV}$.

7. With the increase in the rubber fibre content and an increase in time for both cases, the drying shrinking has increased. Porosity increases due to the reduction of the shrinkage rate owing to rubber particles.

8. Carbonation depth decreased with an increase in rubber content for any substitution level of fine aggregates by a rubber fibre. For geopolymer concrete with $30 \%$ fine aggregate replacement levels, a peak carbonation depth of $8.0 \mathrm{~mm}$ has been noted, whereas for OPC concrete at 90 days of exposure, a carbonation depth of $9.0 \mathrm{~mm}$ was observed on the same replacement level.

The rubber tyre waste could be efficaciously substituting a portion of fine aggregate to form rubberized geopolymer concrete without effecting its properties.

Author Contributions: Conceptualization, I.L.; methodology, S.L.; Investigation, S.L.; writingoriginal draft, S.L. and I.L.; writing-review \& editing, D.N. and R.G.; visualization, S.L., I.L., D.N. and R.G.; supervision: R.G. and D.N. All authors have read and agreed to the published version of the manuscript.

Funding: The writers appreciative of the monetary assistance for this study under the Women Scientist Scheme (sanction number SR/WOS-A/ET-1016/2015) from the Department of Science and Technology in New Delhi.

Data Availability Statement: Not applicable.

Conflicts of Interest: The authors declare no conflict of interest. 


\section{References}

1. Luhar, S.; Cheng, T.W.; Nicolaides, D.; Luhar, I.; Panias, D.; Sakkas, K. Valorisation of glass wastes for the development of geopolymer composites-Durability, thermal and microstructural properties: A review. Constr. Build. Mater. 2019, $222,673-687$. [CrossRef]

2. Davidovits, J. Geopolymer Chemistry and Applications, 4th ed.; J. Davidovits: Saint-Quentin, France, 2015.

3. Aly, A.M.; El-Feky, M.S.; Kohail, M.; Nasr, E.S.A. Performance of geopolymer concrete containing recycled rubber. Constr. Build. Mater. 2019, 207, 136-144. [CrossRef]

4. Pacheco-Torgal, F. Introduction to handbook of alkali-activated cements, mortars and concretes. In Handbook of Alkali-Activated Cements, Mortars and Concretes; Woodhead Publishing: Cambridge, UK, 2015; pp. 1-16.

5. Chen, R.; Li, Q.; Zhang, Y.; Xu, X.; Zhang, D. Pyrolysis kinetics and mechanism of typical industrial non-tyre rubber wastes by peak differentiating analysis and multi kinetics methods. Fuel 2019, 235, 1224-1237. [CrossRef]

6. Fan, Y.; Fowler, G.D.; Zhao, M. The past, present and future of carbon black as a rubber reinforcing filler-A review. J. Clean. Prod. 2020, 247, 119115. [CrossRef]

7. Why Source from Malaysia? Retrieved from Malaysian Rubber Export Promotion Council. 2014. Available online: http: // www.mrepc.com/industry/industry.phpon (accessed on 12 November 2014).

8. Natural Rubber Statistics 2014. Retrieved from Lembaga Getah Malaysia. Available online: www.lgm.gov.my/nrstat/nrstats.pdf (accessed on 12 November 2014).

9. Rubber Statistical Bulletin. Rubber Statistical Bulletin, Rubber Board October-December 2017; Ministry of Commerce and Industry, Government of India: New Delhi, India, 2017.

10. Shulman, V.L. Tire recycling. In Waste; Elsevier Inc.: Brussels, Belgium, 2019; pp. 489-515.

11. ETRMA. End-of-life Tyre Report. Tyre and Rubber Recycling Magazine; European Tyre \& Rubber Manufacturers' Association (ETRMA): Brussels, Belgium, 2015; ELT management.

12. Diaz, R.; Colomines, G.; Peuvrel-Disdier, E.; Deterre, R. Thermo-mechanical recycling of rubber: Relationship between material properties and specific mechanical energy. J. Mater. Process. Tech. 2018, 252, 454-468. [CrossRef]

13. Yilmaz, A.; Degirmenci, N. Possibility of using waste tire rubber and fly ash with Portland cement as construction materials. Waste Manag. 2009, 29, 1541-1546. [CrossRef] [PubMed]

14. Parveen, S.D.; Sharma, A. Rubberized Concrete: Needs of Good Environment (Overview). Int. J. Emerg. Technol. Adv. Eng. 2013, 3, 192-196.

15. Ganjian, E.; Khorami, M.; Maghsoudi, A.A. Scrap-tyre-rubber replacement for aggregate and filler in concrete. Constr. Build. Mater. 2009, 23, 1828-1836. [CrossRef]

16. Thokchom, S.; Ghosh, P.; Ghosh, S. Performance of Fly ash Based Geopolymer Mortars in Sulphate Solution. J. Eng. Sci. Technol. Rev. 2010, 3, 36-40. [CrossRef]

17. Luhar, S.B.; Chaudhary, S.; Dave, U.V. Effect of different parameters on the compressive strength of rubberized geopolymer concrete. In Multi-Disciplinary Sustainable Engineering: Current and Future Trends; CRC Press: Boca Raton, FL, USA, 2016; pp. 77-86.

18. Luhar, S.; Chaudhary, S.; Luhar, I. Thermal resistance of fly ash based rubberized geopolymer concrete. J. Build. Eng. 2018, 19, 420-428. [CrossRef]

19. Luhar, S. Performance Evaluation of Rubberized Geopolymer Concrete and Fly Ash Based Geopolymer Mortar. PhD Thesis, Malaviya National Institute of Technology, Jaipur, India, 2018.

20. Luhar, S. Fly Ash and Slag Based Geopolymer Concrete, Experimental Facts; Lambert Acedamic Publication, Europe: Chisinau, Republic of Moldova, 2015.

21. IS: 3812-1981. Specification for y Ash for Use as Pozzolana and Admixture; Bureau of Indian Standards: New Delhi, India, 1981.

22. Luhar, S.; Chaudhary, S.; Luhar, I. Development of rubberized geopolymer concrete: Strength and durability studies. Constr. Build. Mater. 2019, 204, 740-753. [CrossRef]

23. IS: 383-1970. Specification for Coarse and Fine Aggregate from Natural Sources for Concrete; Bureau of Indian Standards: New Delhi, India, 1970.

24. IS 10262-2009. Concrete Mix Proportioning—Guidelines; Bureau of Indian Standards: New Delhi, India, 2009.

25. DIN 1048. Testing Concrete. Water Permeability; Part 5, Section 36; German Standards: Berlin, Germany, 1991.

26. ASTM C1585-04. Standard Test Method for Measurement of Rate of Absorption of Water by Hydraulic-Cement Concretes; ASTM Standards: West Conshohocken, PA, USA, 2004.

27. ASTM G109-07. Standard Test Method for Determining Effects of Chemical Admixtures on Corrosion of Embedded Steel Reinforcement in Concrete Exposed to Chloride Environments; ASTM Standards: West Conshohocken, PA, USA, 2013.

28. ASTM C876-15. Standard Test Method for Corrosion Potentials of Uncoated Reinforcing Steel in Concrete; ASTM Standards: West Conshohocken, PA, USA, 2015.

29. Olivia, M. Durability Related Properties of Low Calcium Fly Ash Based Geopolymer Concrete. PhD Thesis, Curtin University of Technology, Australia, 2011.

30. Provis, J.L.; Deventer, J.S.J. Geopolymers, Structure, Processing, Properties and Industrial Applications; Woodhead Publishing Limited: Oxford, UK, 2009.

31. Papworth, F.; Grace, W. Designing for Concrete Durability in Marine Environs, Concrete 85 Conference: The Performance of Concrete and Masonry Structures Brisbane; Institution of Engineers, Australia: Barton, ACT, Australia, 1985. 
32. Adam, A.A.; Molyneaux, T.C.K.; Patnaikuni, I.; Law, D.W. Strength, sorptivity and carbonation of geopolymer concrete. In Challenges, Opportunities and Solutions in Structural Engineering and Construction; CRC Press: Boca Raton, FL, USA, 2009.

33. Rangan, B.V.; Wallah, S.E. Low Calcium y Ash Based Geopolymer concrete: Long-Term Properties; Research Report GC2; Faculty of Engineering Curtin University of Technology: Perth, Australia, 2006.

34. Olivia, M.; Nikraz, H. Durability of Low Calcium Fly Ash Geopolymer Concrete in Chloride Solution. In Proceedings of the 6th Asian Symposium on Polymers in Concrete, Shanghai, China, 29-30 October 2009; pp. 153-161.

35. Bakharev, T. Durability of geopolymer materials in sodium and magnesium sulfate solutions. Cem. Concr. Res. 2005, 35, 1233-1246. [CrossRef]

36. Rilem Technical Committee 32-RCA, Seawater attack on concrete and Precautionary Measures. Mater. Struct. 1985, 18, 223-226. [CrossRef]

37. Tikalsky, P.J.; Carrasquillo, R.L. Inuence of Fly Ash on the Sulfate Resistance of Concrete. ACI Mater. J. 1992, 89, 69-75.

38. Lea, F.M.; Hewlett, P.C. The Chemistry of Cement and Concrete; Edward Arnold: London, UK, 1970.

39. Neville, A.M.; Dilger, W.H.; Brooks, J.J. Creep of Plain and Structural Concrete; Construction Press: Loandon, UK, 1983.

40. Reda, T.M.; El-Dieb, A.S.; Wahab, M.E.; Abdel, H. Mechanical, fracture and micro structural investigations of rubber concrete. J. Mater. Civ. Eng. 2008, 20, 640-649. [CrossRef]

41. Davidovits, J. Properties of Geopolymer Cements, First International Conference on Alkaline Cements and Concretes; Scientific Research Institute on Binders and Materials, Kiev State Technical University: Kyiv, Ukraine, 1994; pp. 131-149.

42. Gourley, J.T.; Johnson, G.B. Developments in Geopolymer Precast Concrete; The International Workshop on Geopolymers and Geopolymer Concrete: Perth, Australia, 2005.

43. Song, S.; Jennings, H.M. Pore solution chemistry of alkali-activated ground granulated blast-furnace slag. Cem. Concr. Res. 1999, 29, 159-170. [CrossRef]

44. Bakharev, T.; Sanjayan, J.G.; Cheng, J.B. Resistance of alkali-activated slag concrete to acid attack. Cem. Concr. Res. 2003, 33, 1607-1611. [CrossRef]

45. Sofi, M.; Deventer, J.S.J.; Mendis, P.A.; Lukey, G.C. Engineering properties of in-organic polymer concretes (IPCs). Cem. Concr. Res. 2007, 37, 251-257. [CrossRef] 